\title{
REACTIONS OF LAND ISOPODS TO LIGHT
}

\author{
CHARLES HARLAN ABBOTT
}

Biological Laboratory, Brown University

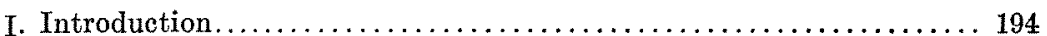

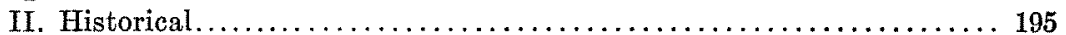

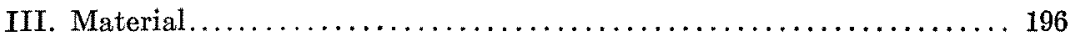

IV. Normal behavior.................................... 197

A. Reactions to light............................ 197

1. Photokinesis............................. 197

2. Phototaxis................................... 197

3. Vision.................................... 198

B. Relation of contact and vision..................... 198

V. Experiments with directive light $\ldots \ldots \ldots \ldots \ldots \ldots \ldots \ldots \ldots \ldots \ldots \ldots$

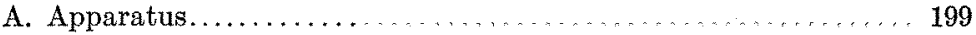

B. Normal reactions................................ 205

1. Positive and negative responses................. 206

2. Orientation................................ 208

3. Angle of negativeness.......................... 211

4. Conclusions.................................. 214

C. Modifiability of the light reactions...................... 215

1. Reaction to different intensities................... 216

2. Effect of repeated stimulation..................... 220

3. Comparison of reactions following exposure to light and to dark.................................... 223

4. Comparison of reactions of individuals from dry and moist

A. Ecological analysis............................... 231

1. Habitat.................................. 232

2. Structural and physiological adaptations................ 232

a. Respiration............................... 232

b. Food...................................... 233

c. Care of young............................ 233

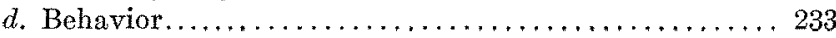


3. Reactions of land isopods................... 234

a. Reactions to humidity and evaporation.......... 234

b. Reactions to contact.................... 235

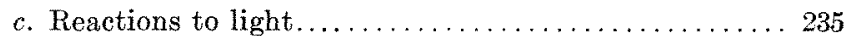

B. The problem of orientation $\ldots \ldots \ldots \ldots \ldots \ldots \ldots \ldots \ldots \ldots \ldots$

1. Direct orientation versus method of trial........... 239

2. Constant intensity versus change of intensity ......... 239

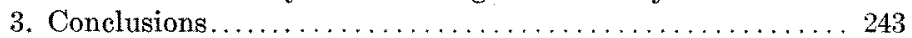

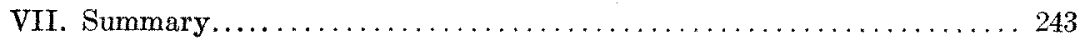

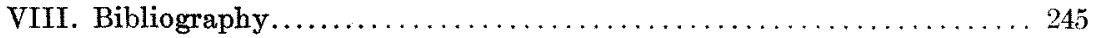

\section{INTRODUCTION}

Land isopods, commonly called sowbugs, have always been of interest as the only Crustacea which are truly terrestrial. However, most previous studies of the adaptation of this group of animals to a land environment have been devoted only to the structure and function of the respiratory organs. The behavior has been almost entirely neglected. Behavior studies, always of interest to comparative psychologists, have been made increasingly important by the recent development of animal ecology into an experimental science, in which behavior is used as a test of the influence of environment. This use of behavior investigations is emphasized in the general ecological works of Adams ('13) and Shelford ('13), and has been applied by Banta ('10) and Allee ('12, '14) to the study of fresh-water isopods.

The present study of land isopods has therefore been undertaken in order to learn if their behavior is of ecological importance. The plan has been, 1) to study the reactions to individual factors of the environment, and 2) to find out if these reactions assist in fitting the animals in question to occupy their present habitat.

This paper reports a study of the behavior of land isopods with respect to one of the most important environmental factors, namely, light. Although the results are considered also from the standpoint of the problems which particularly interest all students of animal behavior, the ecological viewpoint has been the guiding principle throughout.

The experiments were carried on at the Biological Laboratory, Brown University. I wish to thank the authorities of the uni- 
versity and of the laboratory for the opportunities and facilities for research which were furnished me. My greatest debt is to Prof. H. E. Walter, under whose supervision the work was done, for stimulating my first interest in behavior studies, and for helpful suggestions and criticisms at every stage of the investigation.

\section{HISTORICAL}

While naturalists have commonly concluded that land isopods are negatively phototactic, very little experimental work has been done on their reactions. The papers of Cole ('07) and Torrey and Hays ('14) appear to form the entire literature on the subject.

Cole ('07, pp. 371 to 375 ) in "an experimental study of the image-forming powers of various types of eyes" found Oniscus asellus negative to light, but not so uniformly as some other animals, for example the mealworm (larva of Tenebrio molitor Linn.). "Only 45 per cent to 51 per cent of the reactions were away from the light, in excess of those toward the light." Cole exposed Oniscus to illumination from the side, and recorded the place where the animal crossed the circumference of a circle which had a radius of $10 \mathrm{~cm}$. The intensity of the light used varied from 1.5 to 5 candle meters. Cole further found that Oniscus shows a slight discrimination between two sources of light of different diameters which deliver the same intensity on the animal.

Torrey and Hays ('14), working on the orientation of Porcellio scaber, recorded that the animal has a negative response to light, and may be oriented very accurately, 1) by a constant light from behind, 2) by a sudden exposure to lateral light, or 3) by a "sudden exposure to light from the front at angles between $90^{\circ}$ and $15^{\circ}$." "When exposed suddenly to light coming from the front at angles less than $15^{\circ}$, Porcellio moved with less. consistency away from the light, but the reactions were, on the whole, markedly negative." These authors concluded that the orientation of this species is direct, and is not brought about by selection of random movements. 
In the experiments of Torrey and Hays the source of illumination was a Mazda bulb held near the animal. No attempt was made to measure the intensity, but apparently all the work was done with rather high intensities.

Many of the questions which arise with regard to the light reactions of land isopods are not answered by either of the papers just referred to. The present study is an attempt to gain a more thorough understanding of the reaction of land isopods to light, in order to interpret the ecological significance of the behavior.

\section{MATERIAL}

The common species of land isopods belong to the superfamily Oniscoidea and to the family Oniscidae. They are favorable for experimental work because they are abundant, are generalized in their mode of life, and are suited to life in a laboratory. The species Oniscus asellus Linn. was used chiefly for the study, but for comparative purposes two other common species, Porcellio rathkei Brandt and Porcellio scaber Latreille, were also tested in many of the experiments. Complete descriptions of these species are found in Richardson's Monograph (Richardson, '05), and it is not necessary to repeat them here. Various points in the description important from an environmental standpoint, particularly differences between the genera, are given in succeeding pages.

As sowbugs live normally under almost any object that furnishes concealment together with a certain degree of moisture, and as they frequently invade houses, it is not difficult to duplicate their natural surroundings in the laboratory. They were kept in round glass dishes, containing earth, dry leaves, and bark, and covered to prevent evaporation. To allow for possible results of differences in temperature, some were placed in ordinary heated rooms, while others were left out of doors in wooden boxes. Attempts to keep them alive outside the building during the winter months were, however, unsuccessful. Otherwise many of them lived an apparently normal life for several months in the various habitats, and some which were kept in a warm room produced broods of young in December. 
IV. NORMAL BEHAVIOR

\section{A. REACTIONS TO LIGHT}

Animals respond to photic stimuli by three methods:

1. Increased or decreased activity, without orientation. (Photokinesis.)

2. Definite orientation with respect to the source of light, usually accompanied by locomotion toward or away from the light. (Phototaxis.)

3. In animals with image-forming eyes, response to some sort of image made upon the photoreceptive cells. (Vision.)

Inasmuch as sowbugs live in concealed places, the part which light normally plays in their activity is not easily observed. It is, however, clear that they can become accustomed to living in the ordinary daily rhythm of light and dark, because they lived a normal life for weeks in the laboratory under these conditions.

\section{Photokinesis}

Sowbugs appear to respond to sudden increases in intensity of light, both when they are exposed by the overturning of a $\log$ under which they are concealed, and, in the laboratory, when a near-by artificial light is turned on. Two types of response follow under either of the described conditions:

1. Increased activity.

2. Complete cessation of activity.

If the response is one of increased activity, the animals usually keep moving until they reach concealment or, at least, partial concealment in a crevice. The individuals which are inactive at first later become active and seek a more protected situation. No sowbugs are left in sight a short time after a log which has concealed them is overturned.

\section{Phototaxis}

Under the conditions just described, the light is too diffuse to bring about any definite orientation of the isopods. When, 
however, they accidentally start to wander out from dark cavities, a definite phototactic reaction probably turns them back into the dark again. This behavior is difficult to observe in the field, and analysis is, moreover, complicated by reaction to contact.

Simple experiments show that land isopods have a phototactic response to light, even when the light is somewhat diffuse. For example, at 4 P.M. on January 19th, when the light entering the room through a north window was becoming rather dim, individuals of Oniscus, placed on a table several feet from the window, definitely and consistently turned away from the light and traveled in the opposite direction. Such experiments show that these animals have a definite negative phototaxis in ordinary daylight.

The experiments in the following sections are devoted to analysis of this reaction.

\section{Vision}

Land isopods have rather primitive compound eyes, and are to be classed among the animals which have the beginning of vision. As they live constantly in the dark, it does not seem probable that vision plays any appreciable part in their normal life. Observation of the use of the antennae in ordinary isopod activity indicates that vision is of much less importance than reaction to contact in the ordinary life of these animals.

\section{B. RELATION OF CONTACT AND VISION}

The antennae, the most important contact organs of the isopod, are in constant use during ordinary locomotion. They are extended in front of the head and the tips are repeatedly touched to the substratum. The animal often pauses and waves its antennae about in the air or rubs them over any object which chances to be in its path. The antennae are used to test the nature of the environment in a way similar to that in which a blind person, by passing the finger-tips over objects and by the use of a cane when walking, uses the sense of contact as a substitute for the sense of sight. 
When the isopod is at rest, the antennae are often spread on the substratum before it. They are frequently moved independently of the rest of the body either just before locomotion begins or, sometimes, at the moment when the animal pauses before changing the direction of its course. When the animal is stimulated. by directive light, similar movements of the antennae usually occur before locomotion is started. They are described by Torrey and Hays ('14) as analogous to the so-called 'random movements' of the earthworm or blowfly larva.

Another common movement of sowbugs, bothduringordinary activity and when stimulated, is that of 'wiping' or 'cleaning' the antennae. This 'cleaning,' which occurs in other higher Crustacea as well, consists in passing the first walking leg over the antenna as if cleaning it.

The importance of the antennae is shown further by observation of the locomotion after the antennae are removed. Without antennae, obstructions in the path are not usually avoided until the head or the anterior walking legs come in contact with them. On the other hand, according to Torrey and Hays ('14), "totally blind individuals avoid obstacles with the ease of normal individuals." These results following blinding and removal of antennae indicate that the eyes are not normally used for vision.

\section{EXPERIMENTS WITH DIRECTIVE LIGHT}

\section{A. APPARATUS}

The experiments were performed in an experimental darkroom in the basement of the Arnold Biological Laboratory, Brown University. A description will be given of the apparatus which was employed after applying the 'trial and error method' to the devising of apparatus. A table, $122 \times 75 \mathrm{~cm}$., painted. dead black, was placed in the center of the room, under a convenient overhead light. This table, with space for the observer, was surrounded by a black curtain which cut off both the dim light from the ventilator of the room and reflections from all other objects which were not painted black. 
At one end of the table was placed a wooden box, black both inside and outside, containing the source of light-a 60 -watt, 250-volt Mazda lamp. To insure symmetrical illumination of both sides of the field, the lamp was placed in a vertical position in the box. The light passed out through a horizontal slit, $41 \times 3 \mathrm{~mm}$., in a diaphragm. The lower edge of this slit was 5 $\mathrm{mm}$. above the table top, insuring the illumination of the surface of the table and at the same time allowing the light to strike the eyes of the isopod from a horizontal direction. The slit was covered with thin paraffined paper in order to make a source of even illumination. The relation between the table top and the source of light is shown in figures 1 and 2.

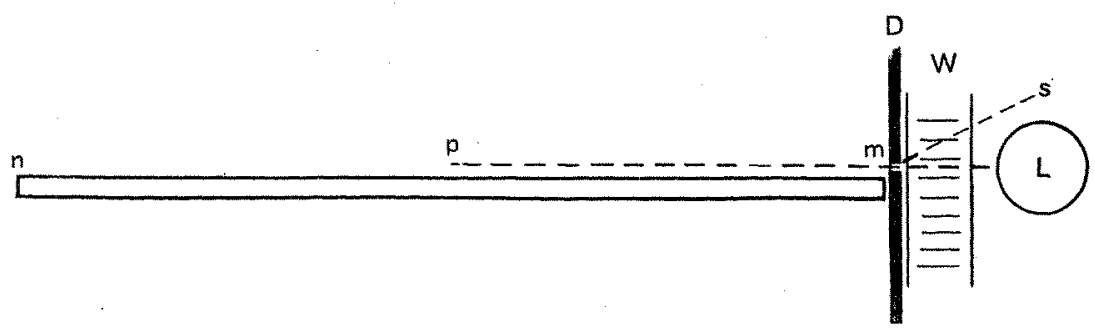

Fig. 1 Vertical diagram of apparatus: $m n$, table top; $D$, diaphragm; $s$, slit in diaphragm through which light passes; $L$, light; $W$, rectangular jar of distilled water to cut out heat; $p$, position where animals were placed; $m p$, path of light to point $p$.

A horizontal field, $60 \times 40 \mathrm{~cm}$.. divided into squares $10 \mathrm{~cm}$. on a side, was marked out or $\mathrm{i}$. part of the table next to the light (fig. 2). This gave an area with the intensity gradually diminishing both from the sourve of light to the opposite end of the field and from the center to the sides. As the slit in the diaphragm through which the light passed was only $41 \mathrm{~mm}$. in length, dark corners (fig. 2, $c$ and $c^{\prime}$ ), were left at the sides and not included in the experimental field. Black strips of wood were placed along the lines $e f$ and $j k$ to shut off possible side reflections. The diaphragm was $5 \mathrm{~mm}$. from the edge of the field.

In most of the experiments the animals were exposed to the light after they had been placed in the center of the field, i.e., 
$30.5 \mathrm{~cm}$. from the diaphragm and $20 \mathrm{~cm}$. from the sides of the field. A circle with a radius of $10 \mathrm{~cm}$. was drawn about this point as a center, and was divided into sixteen sectors, which were numbered 1 to 8 on each side of the central axis $m n$ (fig. 2).

The intensity of the light was measured by means of a Macbeth illuminometer, which was kindly loaned by Prof. W. E. Kenerson, of the Engineering Department. Intensities in candle meters (C.M.) of the principal points of the field, determined

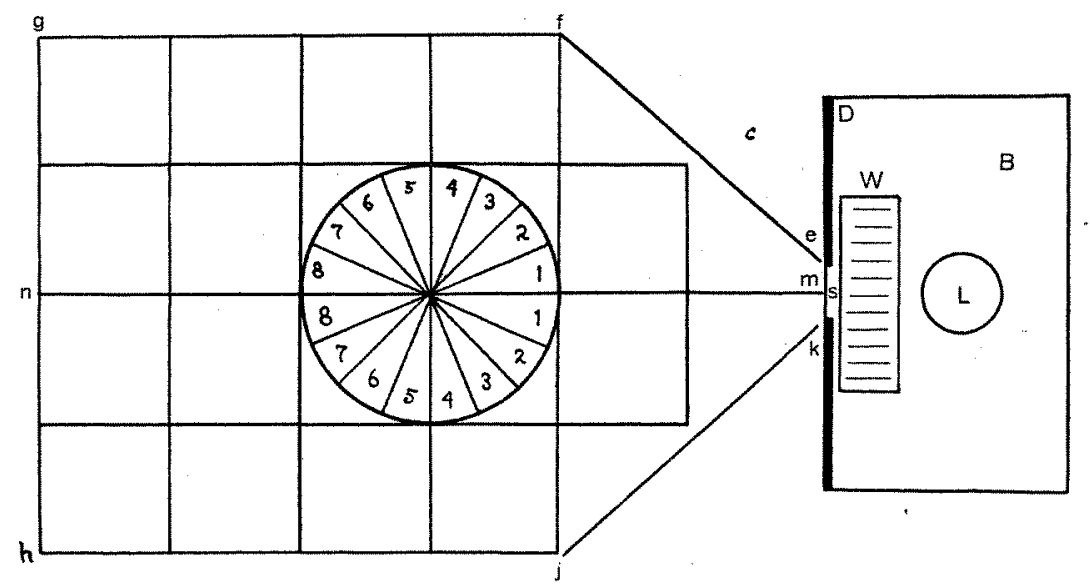

Fig. 2 Horizontal diagram of apparatus: efghjk, experimental field, divided into squares $10 \mathrm{~cm}$. on a side, with a circle of $10 \mathrm{~cm}$. radius at the center; $m n$, central axis of field, receiving the most intense light; $c$ and $c^{\prime}$, dark corners; $B$, box containing light; $L$, light; $D$, diaphragm; $s$, slit in diaphragm; $W$, rectangular jar of distilled water to cut out heat.

early in the experiments, are indicated in figure 3. The intensities at three points along the axis $m n$, i.e., at $20.5,30.5$, and $40.5 \mathrm{~cm}$. from the diaphragm, were determined with considerable accuracy. The intensities of the other points indicated were less easily determined, due to the angles at which it was̀ necessary to make the readings and to the rapidly decreasing light on the sides of the field. This difficulty will account for the differences in the readings from the two sides. The constancy of illumination throughout the experiments is indicated by a reading of 
12.79 C.M. for the central point, made six weeks after the reading of 12.955 C.M. recorded in figure 3.

It can be seen from figure 3 that an animal starting from the central point will go into a region of diminished intensity unless it travels into the quadrant of the circle toward the source of

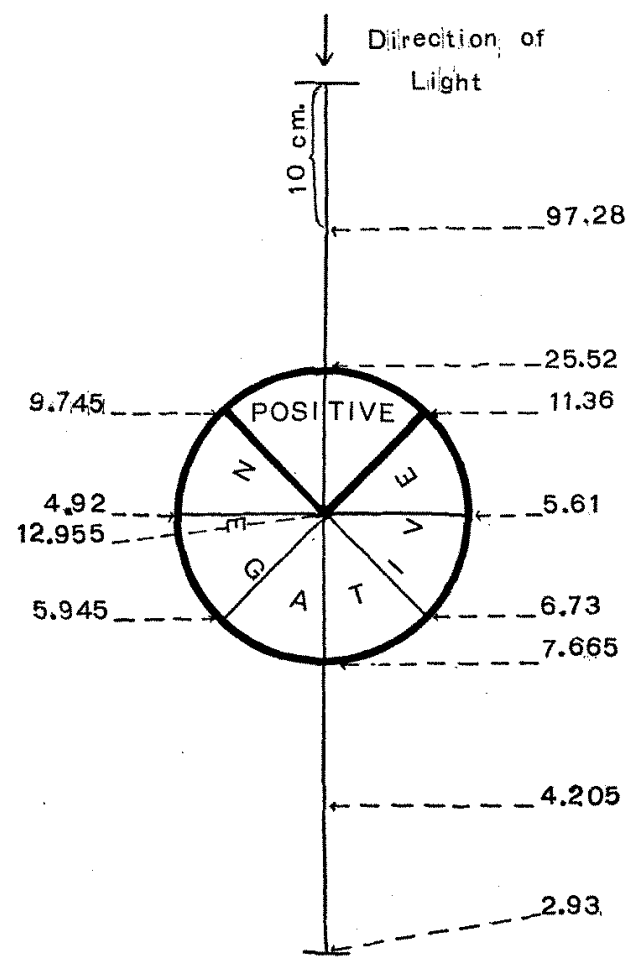

Fig. 3 Diagram of experimental field, showing intensities of light in C.M. at principal points of the field, measured with Macbeth illuminometer. Heavy black line shows the division of the circle into two parts, negative and positive.

light. This fact makes possible a division of the circle into the two parts shown in figure 3 . If the animal leaves the circle in the quadrant nearest the light, it goes into a region of increased illumination, and hence shows a positive response. If it goes in any other direction, the response is negative. 
For convenience in manipulating the animals, small cardboard boxes were used, a little longer than the animal and just wide enough to enclose it without allowing it to turn around (fig. 4). When the sowbug had been shoved to the desired position, the box was removed, and the course taken by the animal was observed and recorded.

In the experiments the isopod was tested successively in four different positions, namely, facing the light (A), facing away from the light (B), with the right side illuminated (C), and with. the left side illuminated (D). This was to eliminate errors due to a possible tendency of the isopod to travel in the direction in which it was already headed.

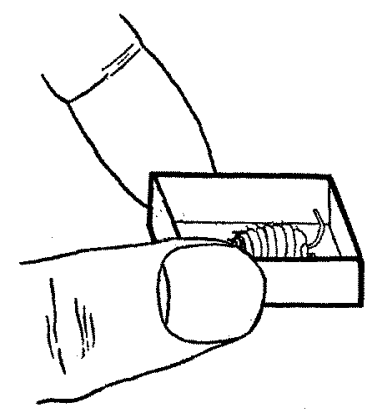

Fig. 4 Diagram of frame with which animals were manipulated on the table top.

The reactions were recorded on printed sheets of paper like that shown in figure 5 . It contains four diagrams of the experimental field, the squares corresponding to the $10-\mathrm{cm}$. squares on the table. With the aid of the squares it was possible for the observer to duplicate the course of the animal with considerable accuracy. The four diagrams were used for the four positions A, B, C, D just referred to. Each record consisted of twenty trials, five each in the four positions. These were made in the order A, B, C, D, A, B, etc., to avoid effects of immediate repetition of the same stimulus. The responses were numbered in the order in which they occurred in the series. Figure 5 is a typical record of the reactions of a normally negative Oniscus. 


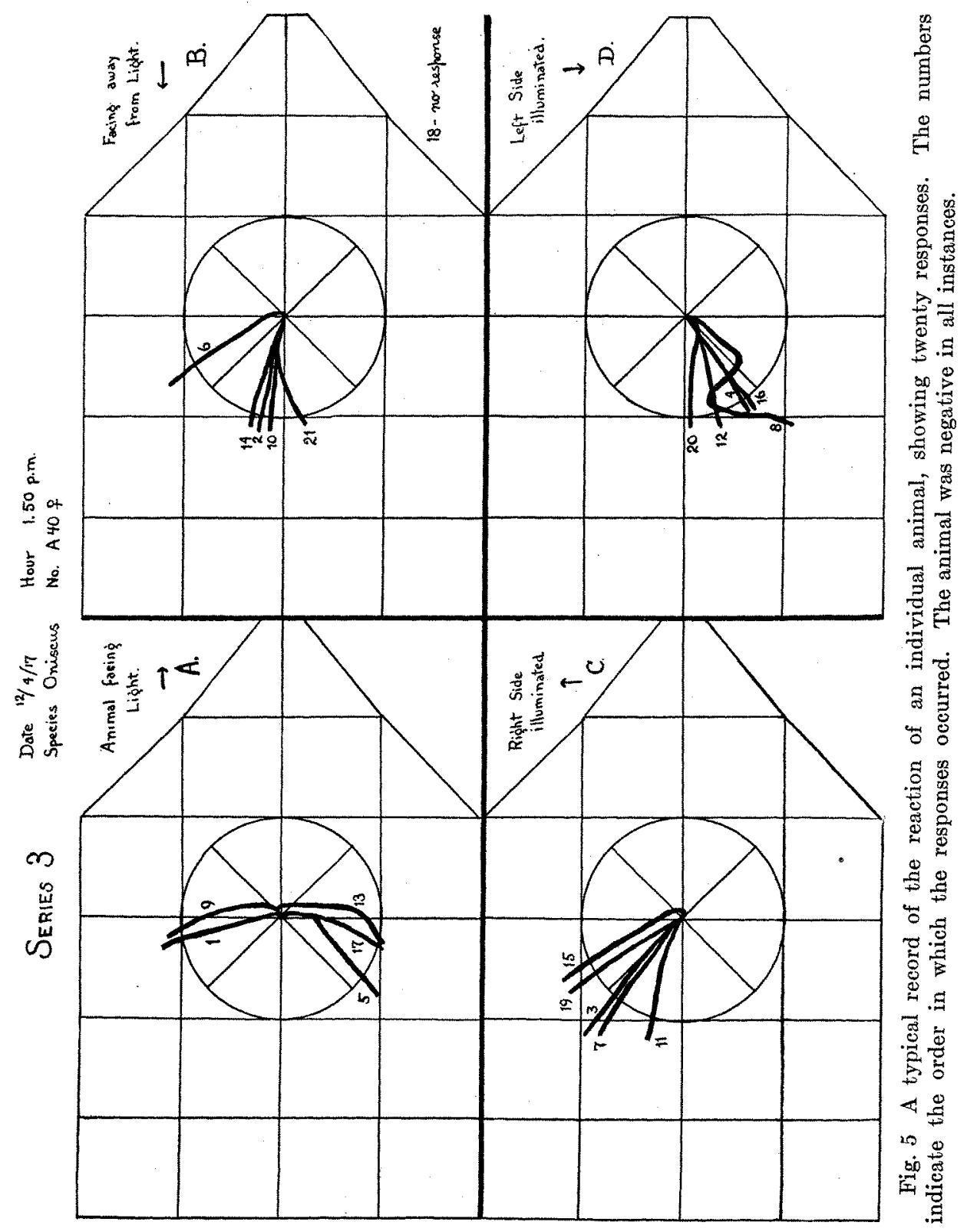




\section{B. NORMAL REACTIONS}

The actual record of the single set of responses shown in figure 5 gives an idea of the usual behavior of Oniscus. That this individual was unquestionably negative to light is shown by a comparison of the reactions in the four positions. The only instance in which the animal continued in the direction in which it was headed occurred when it was illuminated from behind and movement straight ahead carried it away from the light. In all other cases it turned very decidedly away from the source of illumination.

Three different conditions may be noted in the activity of the animal when the box was removed, exposing it to the light: 1) the animal had not come to rest, and merely continued in locomotion; 2) the animal had come to rest, but started locomotion at once when exposed to the light; 3) the animal had come to rest, and did not start locomotion at once when exposed to the light. On account of this variation in the initial conditions, these experiments with directive light do not show whether locomotion was an effect of stimulation by light. The matter is further complicated by the fact that handling the animals may have had an activating effect, an inhibitory effect, or, as is most probable, sometimes one and sometimes the other. However, as these experiments were a test only of the directive influence of light when the animal was already in locomotion, the question whether more than one of these factors entered into the cause of the locomotion need not be considered. For this reason no record was made of the interval before response in most cases. When there was a delay before response, the antennae were often kept moving, particularly just before locomotion was started, although few if any of these movements could properly be called 'trial movements.'

Much individual variation was observed. While the direction of locomotion was usually determined by the light, there were many turns and circles, the causes of which were not so easily analyzed. An example is shown in figure $5, \mathrm{D}$, response no. 8 . 
An examination of a large number of records showed that Oniscus is decidedly negative to light. This conclusion is shown best, however, by applying to the records more than one method of analysis, in order to give a clearer idea of what is involved in the negative reaction. Three methods will be described on the basis of results obtained while studying the individual behavior of these isopods, on successive days. The three animals which will be particularly considered are designated as A 10, A 11, and A 12. They were placed in all cases in the center of the field, as in the typical method described, and exposed to an average intensity of 12.955 candle meters.

In making each record, the sex of the animal was recorded. However, no differences were found between the reactions of the two sexes, so that the results of both were used indiscriminately in compiling tables and angles.

\section{Positive and negative response - first method of analysis}

This method of tabulating results is shown in table 1 , which summarizes the results from Oniscus A 10, extending over seventeen days.

Responses are classified as positive or negative according to the grouping explained in figure 3 . When the animal crossed the circle within the positive quadrant, the response was recorded as positive; otherwise, it was considered negative, because the animal went into a region of diminished intensity. The letters A, B, C, D refer to the four positions in which the animal was placed with reference to the light.

The results are given in percentages of each kind of response. The positive responses number 5.9 per cent, and the negative responses, 94.1 per cent. The variation in the four columns $\mathrm{A}, \mathrm{B}, \mathrm{C}$, and $\mathrm{D}$ is slight, showing that the direction in which the isopod was headed made little difference in the nature of the response. This Oniscus was thoroughly negative to light, although in a few isolated instances it went toward the light. If the positive response were 25 per cent of the total, it might be concluded that the animal was indifferent to light, as the posi- 
TABLE 1

Reaction of Oniscus $A 10$ to directive light of 12.955 C.M., showing results of daily tests for 17 days. Tests were made with the animal facing the light $(A)$, facing away from the light $(B)$, and illuminated on the right $(C)$ and left $(D)$ sides

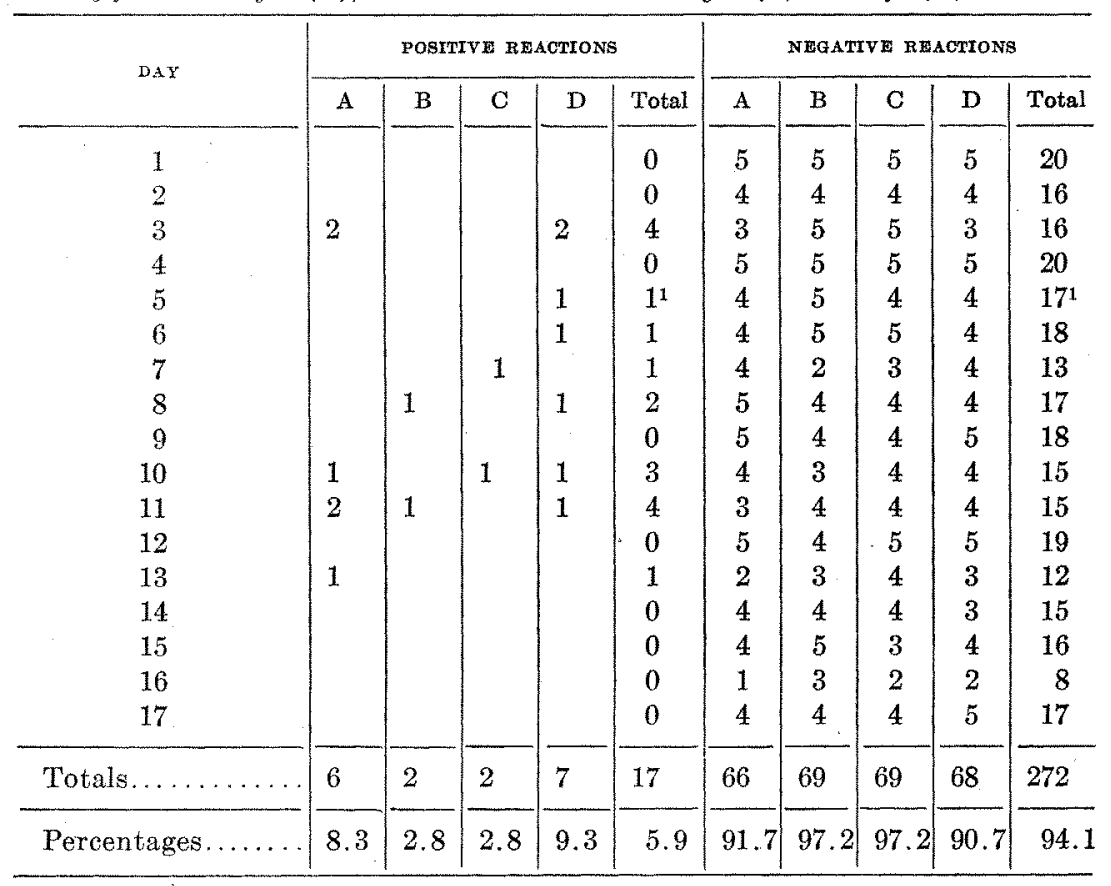

1. When less than 20 responses are recorded, the animal failed to respond in the other instances.

tive section of the field is only 25 per cent of the whole. However, the 5.9 per cent calculated shows that the animal was unquestionably negative. The occasion when it would naturally have gone toward the light if it were indifferent, was when it was facing the light at the start, but even under that condition it turned away in 91.7 per cent of the trials.

A similar tabulation of percentages is shown in table 2 for Oniscus A 11, tested for fifteen days.

A higher record of positiveness was made by Oniscus A 12, which received fifteen daily tests. Most of the positive responses came in the first four days, the animal being 45 per cent positive on the first day. After the fourth day, the reaction was as 
Summary of reaction of Oniscus A 11, to directive light of 12.955 C.M., showing results of daily tests for 15 days. Tests were made with the animal facing the light $(A)$, facing away from the light $(B)$, and illuminated on the right $(C)$ and left $(D)$ sides

\begin{tabular}{|c|c|c|c|c|c|c|c|c|c|c|}
\hline \multirow{2}{*}{ DAY } & \multicolumn{5}{|c|}{ POSITYVE REACTIONS } & \multicolumn{5}{|c|}{ NEGATIVE REACTIONS } \\
\hline & A & B & $\mathrm{C}$ & $\mathrm{D}$ & Total & A & $B$ & C & D & Total \\
\hline Totals. & 4 & 0 & 3 & 5 & 12 & 59 & 61 & 61 & 57 & 238 \\
\hline Percentages. & 6.3 & 0.0 & 4.7 & 8.1 & 4.8 & 93.7 & 100 & 95.3 & 91.9 & 95.2 \\
\hline
\end{tabular}

typically negative as that of either of the other individuals just described. Table 3 shows how this isopod gradually changed from indifferent or positive to negative.

As an indifferent animal would be about 25 per cent positive, the 45 per cent recorded on the first day shows a considerable degree of positiveness on that day.

This method of classification shows that these isopods, when stimulated by directive light, usually avoid the light by locomotion to regions of lower intensity. As the light stimulus is received through the eyes, it is further important to know the result of unequal stimulation of the two eyes. This is shown by a study of the angle of the course taken by the animal after it has been exposed to the light.

\section{Orientation-second method}

As was shown in figure 2 , the circle on the light field was divided into sixteen sectors, numbered 1 to 8 on each side of the central axis $m n$. If the homologous classes on the right and left sides are grouped together, the responses of any individual isopod can be divided into eight degrees of negativeness, according to the sector of the circle which the animal crossed after exposure to the light.

The same records which were summarized in tables 1 and 3 are shown graphically in figures 6 and 7 , after tabulation according to this second method. Figure 6 shows the degree of negativeness of Oniscus A 10, the numerals on the abscissae corresponding 
TABLE 3

Reaction of Oniscus $A 12$ to directive light of 12.955 C.M., showing results of daily tests for 15 days. Tests were made with the animal facing the light $(A)$, facing away from the light $(B)$, and illuminated on the right $(C)$ and left $(D)$ sides

\begin{tabular}{|c|c|c|c|c|c|c|c|c|c|c|}
\hline \multirow{2}{*}{ DAY } & \multicolumn{5}{|c|}{ POBTTIV REACTION } & \multicolumn{5}{|c|}{ NEGATIVE RMACTIONS } \\
\hline & A & B & C & D & Total & A & $\mathrm{B}$ & $\mathrm{C}_{\tau}$ & $\mathbf{D}$ & Total \\
\hline 1 & 3 & 1 & 3 & 2 & 9 & 2 & 4 & 2 & 3 & 11 \\
\hline 2 & 2 & & & 3 & 5 & 3 & 5 & 5 & 2 & 15 \\
\hline 3 & 2 & & 2 & & 4 & 3 & 5 & 3 & 5 & 16 \\
\hline 4 & 2 & & 2 & & 4 & 2 & 4 & 3 & 4 & 13 \\
\hline 5 & & & & 1 & 1 & 2 & 4 & 2 & 3 & 11 \\
\hline 6 & & & & & 0 & 3 & 4 & 4 & 3 & 14 \\
\hline 7 & & & & & 0 & 3 & 4 & 5 & 2 & 14 \\
\hline 8 & 2 & & & & 2 & 3 & 5 & 5 & 5 & 18 \\
\hline 9 & & & & 1 & 1 & 5 & 5 & 5 & 5 & 20 \\
\hline 10 & & & & & 0 & 4 & 5 & 4 & 5 & 18 \\
\hline 11 & & & & 1 & 1 & 5 & 5 & 5 & 4 & 19 \\
\hline $11^{1}$ & & & & & 0 & 2 & 2 & 4 & 2 & 10 \\
\hline 12 & & & & & 0 & 5 & 5 & 5 & 5 & 20 \\
\hline 13 & 1 & & & & 1 & 1 & 4 & 4 & 2 & 11 \\
\hline 14 & 1 & & & & 1 & 3 & 4 & 5 & 4 & 16 \\
\hline 15 & 1 & & & & 1 & 1 & 4 & 3 & 3 & 11 \\
\hline Totals.............. & 14 & 1 & 7 & 8 & 30 & 47 & 69 & 64 & 57 & 237 \\
\hline Percentages. & 23.0 & 1.4 & 9.9 & 12.3 & 11.2 & 77.0 & 98.6 & 90.1 & 87.7 & 88.8 \\
\hline
\end{tabular}

${ }^{1}$ A second set of responses was recorded on the eleventh day.

to the eight degrees of negativeness just referred to and the numerals on the ordinates being the number of responses which fall into each of these eight classes. The lines A, B, C, D represent the four positions with respect to the light in which the animal was placed, while the dotted line is the average of the four positions.

As would be expected, the greatest degree of negativeness is when the animal is headed away from the light, and the lowest, when facing the light. As only data in classes 1 and 2 on the abscissa indicate a positive response, all of the curves show that this isopod was thoroughly negative. There is a close correspondence between the nearly identical reactions in positions $\mathrm{C}$ and $\mathrm{D}$ and the average for all positions. This indicates that the 


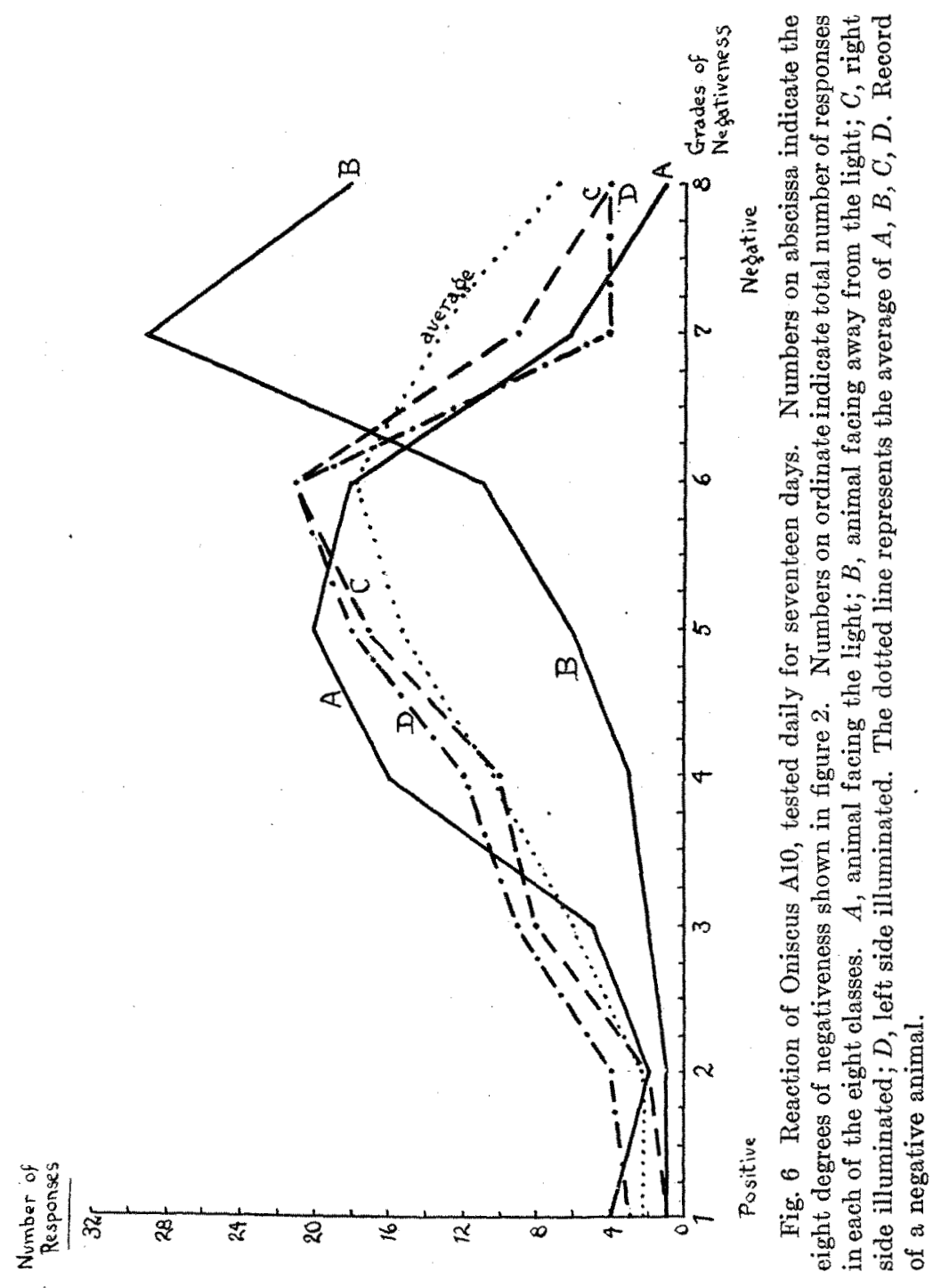


reaction when the animal is illuminated on the side shows the true degree of negative reaction, and, moreover, that the results in positions $A$ and $B$ balance each other, so that the average in all four positions is a suitable control for the correctness of the results from stimulation on the side.

The reaction of Oniscus A 12 is given in figure 7. These curves show more positive responses than occurred in A 10, due to the many instances in which this isopod went toward the light during the first four days. From the average for the entire period of the experiment, it appears that $A 12$ became the more negative of the two animals, because, in spite of the degree of positiveness at first, the average in figure 7 shows the greatest number of responses in classes 7 and 8 on the abscissa, while in figure 6 classes 5 and 6 are the largest. In figure 7 the correspondence between the average reaction and the reaction in positions $\mathrm{C}$ and $\mathrm{D}$ is not quite so close as in figure 6 , but the average is much nearer to these than to the reactions in positions $\mathrm{A}$ and $\mathrm{B}$.

The graphical method shows more definitely what is involved in the negative reaction than was shown by a simple enumeration of positive and negative responses. The animals regularly turned away from the light in whatever position they were originally. placed, except that when they were already headed away from the light they nearly always traveled in the direction in which they were headed. From this method of analysis it may be concluded that Oniscus is definitely oriented by the light and that the response involves something more than moving at random into a lower intensity.

\section{Angle of negativeness - third method}

This method was devised to express the degree of negativeness of any one individual isopod or group of isopods by a single figure, which might be used for comparison with the results obtained in succeeding experiments. For this purpose the angle of negativeness was chosen. This term will be applied to the average angle of the course taken by the animal with respect to the position of the source of light. 


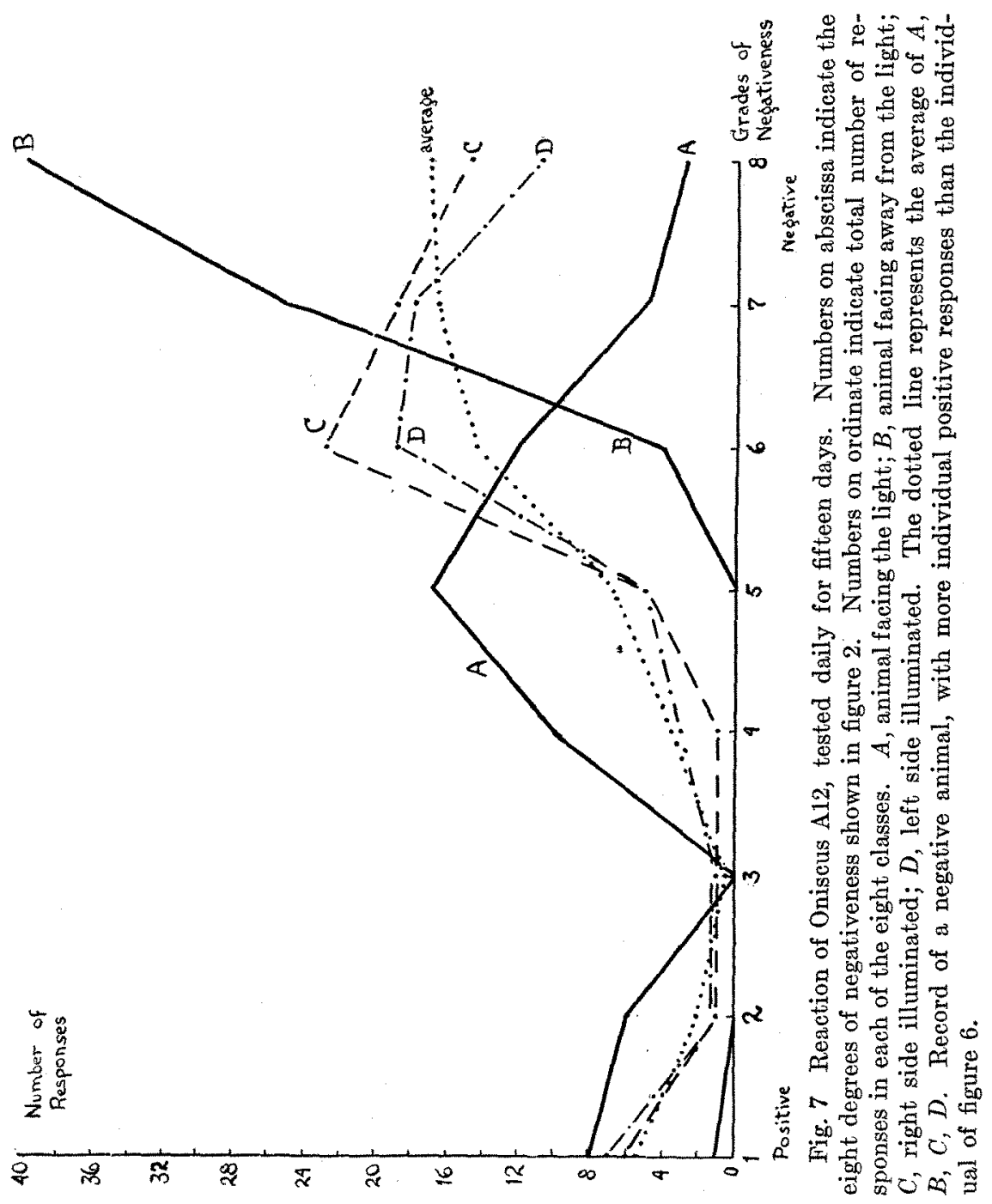


The method of calculation is as follows: Each response is given the number of the sector in which it falls as in the second method (fig. 2). For example, in the records of class $\mathrm{A}$ in figure 4 , four of the responses fall into sector 5 and one into sector 6 . The average of the five responses is thus 5.2. The middle points of the eight sectors, expressed in terms of angular deviation from the central axis $m n$ are: $1.11 .25^{\circ} ; 2.33 .75^{\circ} ; 3.56 .25^{\circ}$; 4. $78.75^{\circ}$; 5. $101.25^{\circ}$; 6. $123.75^{\circ}$; 7. $146.25^{\circ} ; 8.168 .75^{\circ}$. The difference between each of these figures and the succeeding one is $22.50^{\circ}$, or one-sixteenth of $360^{\circ}$. The figure 5.2 expressed in angles is equivalent to the angle just given for $5,101.25^{\circ}$, plus two-tenths of $22.50^{\circ}$, making $105.75^{\circ}$, the angle of negativeness for the responses recorded in figure $4, \mathrm{~A}$, when the animal was facing the light.

As an application of this method, table 4 expresses the angle of negativeness for the reactions which were shown graphically in figures 6 and 7 .

The table shows that both of these animals were negative, because they turned, on the average, at least $90^{\circ}$ away from the light when they were facing the light, and, respectively, $14^{\circ}$ and $32^{\circ}$ away when they were already at right angles to the light.

The fact that Oniscus A 12 was positive or indifferent on the first day and gradually became negative is shown by the angles, when the animal was stimulated on the side, for the first seven days of the experiment: 1st day, $78.75^{\circ} ; 2$ nd, $96.75^{\circ} ; 3 \mathrm{rd}$, $103.50^{\circ}$; 4 th, $85.50^{\circ}$; 5 th, $108.00^{\circ}$; 6 th, $139.50^{\circ}$; 7 th, $139.50^{\circ}$.

TABLE 4

Angle of negativeness for Oniscus $A 10$ (tested for 17 days) and $A 12$ (tested for 15 days). Intensity of light 12.955 C.M. Tests were made with the animals facing the light $(A)$, facing away from the light $(B)$, and illuminated on the right $(C)$ and left $(D)$ sides

\begin{tabular}{|c|c|c|c|c|c|c|}
\hline ANIMAI & $A$ & B & c & D & $\begin{array}{l}\text { TOTAL } \\
\text { A, B, C, D }\end{array}$ & TOTAL $\mathrm{O}_{*} \mathrm{D}$ \\
\hline 10 & $96.75^{\circ}$ & $135.00^{\circ}$ & $105.75^{\circ}$ & $101.25^{\circ}$ & $108.00^{\circ}$ & $104.625^{\circ}$ \\
\hline 12 & $90.00^{\circ}$ & $155.25^{\circ}$ & $148.50^{\circ}$ & $119.25^{\circ}$ & $130.50^{\circ}$ & 122.40 \\
\hline
\end{tabular}


As an angle of negativeness of $90^{\circ}$ represents the average course of an animal placed at right angles to the light, if it is indifferent to light, the angle for the first day shows that this individual was somewhat positive on that day, because it turned on the average $11.25^{\circ}$ toward the light. This accords with the 45 per cent positive response calculated according to the first method.

The responses in any record fall into three classes with respect to the angle of negativeness:

1. When the animal is facing the light (position A), it is possible to measure only the angle of turning away from the light.

2 . When the animal is facing away from the light (position $\mathrm{B}$ ), it is possible to measure only the angle of turning toward the light.

3. When the light strikes the animal on the side (positions $\mathrm{C}$ and $D$ ) either the angle of turning away from the light or the angle of turning toward the light can be measured.

This difference raised the question whether the angle of negativeness should be measured only from the results in positions $\mathrm{C}$ and $\mathrm{D}$ or from those of the four positions combined. A test series showed that the results are approximately the same, whichever method is used. Of course the smallest angle is obtained when the animal is facing the light and the largest when facing away from the light, but these two extremes balance each other. The series which shows this is given in the section on the comparison of Oniseus and Porcellio (table 10, page 228). Compare also the last two columns in table 4. In the following pages, wherever the angle is given without further explanation, the angle calculated from the positions $\mathrm{C}$ and $\mathrm{D}$ is given.

\section{Conclusions}

a. The individual isopods which have been considered in the preceding pages were, except in the instance of one individual on a single day, definitely negative to light. This is shown by the calculation of a high percentage of negative responses and by the measurement of the average angles through which these animals turned in their movements away from the light. 
$b$. The results which have been analyzed are typical for the species Oniscus asellus. The reaction of nearly all individuals is negative, with only occasional reversals to positiveness. The constancy of these results will be shown in the experiments to be described later in this paper.

c. Nothing has been said as yet about the reactions of Porcellio. The two species of Porcellio are also negative to light, but the reaction is less consistent than that of Oniscus. The difference between the two genera will be shown repeatedly in the following pages, and, finally, will be summarized in the section on the comparison of Oniscus and Porcellio.

\section{MODIFIABILITY OF THE LIGHT REACTIONS}

A consideration of the ecological importance of isopod behavior involves the question whether the behavior is constant or is easily modified by environmental changes. Shelford has pointed out the fallacy of the assumption that the behavior of a given species is a constant characteristic, whatever the environmental conditions. In recent studies of fresh-water animals (Shelford, '14) and marine forms (Shelford, '16), he has shown that behavior characters belong to a community even more than to a species, and that behavior differences between individuals of a single species from different habitats may be greater than those between widely diverse species which occupy the same habitat.

As an illustration of this principle, Allee ('12) has shown differences in the rheotaxis of the fresh-water isopod Asellus communis Say, according as the individuals tested came from ponds or from streams.

Modification of behavior, however caused, is shown in many ways, of which the three following are important: 1) by a partial or entire failure to respond to the stimulus; 2) by an intensification of response; 3 ) by a reversal of response. Allee ('12, '14) obtained the first two of these modifications by subjecting Asellus to various experimental conditions which changed the metabolism of the animal. He found that eonditions similar to 
those of stream life induced a definite positive rheotaxis in pond isopods, while conditions similar to those of pond life decreased the rheotaxis of stream isopods. That these differences are adaptive is shown by the fact that reaction to current is important in the normal life of stream forms, but of less significance for animals that live in quiet water.

The third result, a reversal of response, has been observed in various animals, due to many different causes. The work on this subject is well summarized by Holmes ('16) in a chapter entitled "The Reversal of Tropisms."

The following problems were undertaken, in order to learn whether the behavior of land isopods is constant or is easily changed by external conditions:

1. Reaction to various intensities of light.

2. Effect on reaction of repeated stimulation by the same light intensity.

3. Comparison of reactions following exposure to light and to dark.

4. Comparison of reactions of individuals from dry and moist habitats.

5. Reaction in water.

\section{Reaction to different intensities}

a. Average intensities. Studies of the effect of different intensities were easily accomplished by placing the isopods at various distances from the source of light. The intensities at the points chosen furnished a range from 3 to 100 C.M. The actual intensities, as determined by the illuminometer, are given below.

\begin{tabular}{c|c|c}
\hline POBITION & DIGTANCB FroM DIAPHRAGM (OM.) & INTENGITY \\
\hline & $c m$. & $C . M$. \\
1 & 10.5 & 97.28 \\
2 & 20.5 & 25.52 \\
3 & 30.5 & 12.955 \\
4 & 40.5 & 7.665 \\
5 & 50.5 & 4.205 \\
6 & 60.5 & 2.93 \\
\hline
\end{tabular}


The test was made by three methods: 1) testing individual animals for a series of days, each day at a different intensity; 2) testing several animals from the same habitat on the same day, each animal at a different intensity, and 3) trying the different intensities in turn on each animal.

The experiments showed that the response is in general the same to all intensities which were tried. If an individual isopod is negative it is negative to all intensities, while if it is indifferent, it is alike indifferent to all intensities. This result was obtained by all three of the methods described, so that the different methods furnish a check on each other.

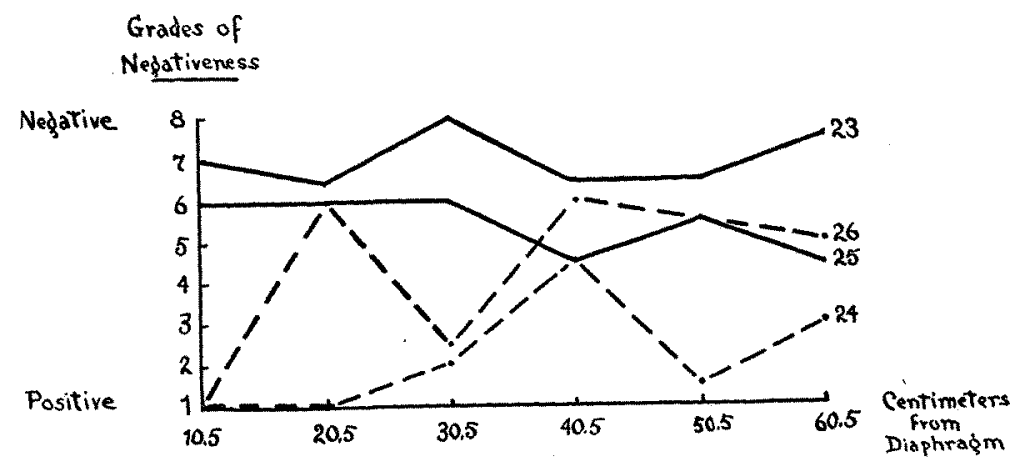

Fig. 8 Reactions to light of different intensities. Two individuals of Oniscus (23 and 25) and two of Porcellio rathkei (24 and 26). Numbers on abscissa indicate distances in centimeters from slit in diaphragm through which light passes. Intensities at each of these points are given in the table on page 216. Numbers on ordinate indicate the eight degrees of negativeness shown in figure 2. Shows no consistent variation corresponding to the intensity.

The third method is perhaps the most satisfactory, because it eliminates errors due to differences between individuals and to variations in 'physiological state' on successive days. It has the disadvantage that the result is based on four responses only (one in each position) at each intensity, rather than on twenty responses.

The reactions of four isopods, classified according to this method, are shown graphically in figure 8 . The numbers on the abscissae indicate the distances from the light, which correspond 
to the intensities given in the above table, while the numbers on the ordinates refer to the eight degrees of negativeness, according to the classification of figure 2 .

In the diagram the reactions of the two individuals of Oniscus (A 23 and A 25) are represented by nearly straight lines, showing approximately the same negative response to all intensities used in the experiment. Porcellio rathkei (A 24 and A 26) has the usual variations for the species, but these bear no relation to the intensity. The figure merely illustrates graphically the conclusions given above.

When tested by the first method described above, Porcellio scaber gave its normal reaction also at a point $5.5 \mathrm{~cm}$. from the diaphragm, where the intensity was approximately 400 C.M.

b. Low iniensities. Some species of animals which are normally negative to light are indifferent to low intensities, while a few are positive under the same conditions. For this reason, a series of tests with low intensities was arranged. These intensities were obtained by using Mazda and carbon lights of lower power and by increasing the distance between the isopod and the source of light.

After finding Oniscus negative to intensities of 0.859 C.M. and 0.648 C.M., a final series was tried with intensities which were too low to be measured directly by the illuminometer, but which could be calculated from illuminometer readings at other points, according to the law of inverse squares. The results in this series, given in table 5 , represent the reaction of ten individuals each of Oniscus and Poreellio scaber at each intensity, the figures referring to the average reaction for each individual, rather than to the individual responses.

As the animals were tested when facing the light only, those which went toward the light were perhaps indifferent instead of positive.

Table 5 shows that Oniscus was negative, even at these low intensities. This was shown so strikingly by the test at the lowest intensity recorded (0.0119 C.M.) that a further description will be given of this particular experiment. The illumination of the table was so slight that the sowbugs were 
TABLE 5

Reactions to low intensities of light. Numbers refer to the average reactions of individual isopods

\begin{tabular}{|c|c|c|c|c|c|}
\hline \multirow{2}{*}{ ISOPODS } & \multirow{2}{*}{ INTENSTTY } & \multicolumn{4}{|c|}{ REACTION } \\
\hline & & Negative & Positive & Indifferent & No response \\
\hline Oniscus. & $\begin{array}{l}\quad C . M . \\
0.169 \\
0.0749 \\
0.0255 \\
0.0119\end{array}$ & $\begin{array}{r}10 \\
7 \\
10 \\
9\end{array}$ & 1 & $\begin{array}{l}2 \\
1\end{array}$ & \\
\hline Percellio... & $\begin{array}{l}0.169 \\
0.0749 \\
0.0255 \\
0.0119\end{array}$ & $\begin{array}{l}6 \\
7 \\
3 \\
7\end{array}$ & $\begin{array}{l}3 \\
2 \\
2 \\
1\end{array}$ & $\begin{array}{l}1 \\
1 \\
2\end{array}$ & $\begin{array}{l}3 \\
2\end{array}$ \\
\hline
\end{tabular}

almost invisible, although scarcely $30 \mathrm{~cm}$. from the eye of the observer. A faint reflection on the chitin covering made it possible, but not easy, to determine the position of the animal, particularly during locomotion. Of course the actual horizontal illumination which reached the eyes of the animal was considerably greater than was reflected to the observer above. In spite of the fact that the light was so dim, Oniscus turned away from it as definitely as from the stronger intensities between 1 and 100 C.M. Nearly all of the individual animals, on starting locomotion, turned directly away, without describing as large an arc as is common when higher intensities are used.

As a control for this experiment, ten individuals of Oniscus were tested immediately afterwards in total darkness. The result showed no orientation to any external stimulus, and in most instances locomotion was in the direction in which the animals were already headed. The actual course taken was determined by means of a flashlight after the isopod had been in the dark long enough to start in a definite direction. As all conditions except exposure to light were the same in the control as in the experiment, the results with low intensities must have been due solely to the light.

According to Patten ('17, p. 260), "It is the abruptness with which orientation is attained, rather than the final accuracy of 
orientation, which shows the results of slight differences in effectiveness of the receptive mechanism." If that be so, the abrupt and definite orientation of Oniscus to low intensities indicates that Oniscus is extremely sensitive to light and is definitely oriented by light.

The reactions of Porcellio to low intensities show as usual more variation than those of Oniscus, but they are in the main negative, and essentially the same as the reactions to higher intensities. They show that Porcellio, as well as Oniscus, is responsive to extremely low intensities of light.

These results are particularly interesting, because Banta ('10) found Asellus communis unresponsive to light of an intensity of 1 C.M. or less. As will be considered later, Oniscus and Porcellio appear to be more sensitive to light than is Asellus, the common fresh-water isopod.

The conclusion to be derived from these experiments is that land isopods are sensitive to a wide range of light intensity and their reaction to all intensities is essentially the same.

\section{Effect of repeated stimulation}

A second condition which might change or reverse the reaction is repeated stimulation. For these experiments, Oniscus, since it is definitely negative, was chosen, in order to watch for a possible reversal from negative to positive phototaxis. The animals were placed facing the light, so that every negative response would necessarily mean a definite turning away from the source of the stimulus. Records were made in each instance of the course taken and of the interval before response. Whenever no response occurred during sixty seconds, the result was recorded as "no response, sixty seconds."

Sixteen individuals were used in these experiments and were given a varying number of successive stimuli: one animal received 100 successive stimuli, three received 60 , one received 40 , five received 30, and six received 20 . The longest time used in testing any one animal was one hour. The first individual mentioned, which gave 100 responses in one hour, was unusually active. 
TABLE 6

Results of experiments testing the infuence of repeated stimulation on Oniscus. The animals were facing the light in all instances. Intensity 12.955 C.M.

\begin{tabular}{c|c|c|c}
\hline RESPONSES & $\begin{array}{c}\text { NUMBER } \\
\text { OF INDTVDUALS }\end{array}$ & $\begin{array}{c}\text { ANGLE OF } \\
\text { NEGATVENESS }\end{array}$ & $\begin{array}{c}\text { INTERVAL IN SECONDS } \\
\text { BEFORE RESPONSE }\end{array}$ \\
\hline $1-10$ & 16 & $81.00^{\circ}$ & 9.25 \\
$11-20$ & 16 & $78.75^{\circ}$ & 21.01 \\
$21-30$ & 10 & $87.75^{\circ}$ & 25.60 \\
$31-40$ & 5 & $90.00^{\circ}$ & 15.56 \\
$41-50$ & 4 & $91.125^{\circ}$ & 16.875 \\
$51-60$ & 4 & $81.00^{\circ}$ & 25.625 \\
\hline
\end{tabular}

${ }^{1}$ The numbers in this column diminish, because the tests of only four individuals were continued through 60 stimuli, others extending only to 40,30 , and 20 .

The results were compiled by dividing the responses into groups of ten successive responses and measuring the average angle of negativeness.

Table 6 , which summarizes the reactions of these sixteen animals, shows no influence of repetition upon the character of the response.

The average turning from the light was as definite after sixty successive stimuli as at first.

Whatever effect was caused by the delay is shown by a lessening of activity as is indicated by the interval before response, shown in the last column of table 6 . The figures are only approximate, as all delays over 60 seconds were counted as 60 seconds in making the averages. The essential conclusion is that after the first few trials there is usually a slight decrease in responsiveness, but from that time on there is little change. The delay is probably due chiefly to the effects of handling, as a similar delay occurs just as readily when the animals are moved about on the table by the same method of manipulation, but not exposed to light at all.

Furthermore, while there were changes in individual behavior which are not shown in the above table, there was no consistent change in phototaxis which could be traced to the effects of repetition. In some individuals the angle of negativeness decreased with continued stimulation, in others it increased, while in still others it passed through both of these variations successively. 
Analysis of the reaction of Oniscus F 2 , exposed to light of 12.955 C.M. for 100 successive stimuli. Duration of experiment one hour

\begin{tabular}{c|c|c}
\hline RESPONSES & ANGLR OF NEGATIVENHSS & $\begin{array}{c}\text { INTERVAL IN SECONDS BEFORR } \\
\text { RESPONSE }\end{array}$ \\
\cline { 2 - 3 } $1-10$ & $49.50^{\circ}$ & 5.5 \\
$11-20$ & $90.00^{\circ}$ & 7.0 \\
$21-30$ & $96.75^{\circ}$ & 7.0 \\
$31-40$ & $74.75^{\circ}$ & 3.0 \\
$41-50$ & $81.00^{\circ}$ & 8.0 \\
$51-60$ & $94.50^{\circ}$ & 15.0 \\
$61-70$ & $40.50^{\circ}$ & 12.5 \\
$71-80$ & $54.00^{\circ}$ & 7.0 \\
$81-90$ & $51.75^{\circ}$ & 9.0 \\
$91-100$ & $42.75^{\circ}$ & 0.0 \\
\hline
\end{tabular}

Some individuals appeared to 'tire out,' others continued active as long as they were tested, but no correlation was observed between delayed reaction and definiteness of turning from the light.

As an example of individual rather than of species behavior, a summary is given in table 7 , of the reaction of Oniseus F 2 which responded to 100 successive stimuli.

The characteristics of this animal were that it was very active without any diminution of activity at the end of 100 stimuli and that it was not as negative to light as are most individuals of this species. In the first ten responses it was indifferent or positive, then it became much more negative for fifty successive responses, after which it became once more somewhat indifferent. These changes are shown in the table by the column for the angles of negativeness. As the animal was not negative at the beginning, this table does not illustrate the usual behavior for the species.

From this series of experiments on repeated stimulation it may be concluded that the phototaxis of Oniscus is not changed or reversed by a long series of successive responses. Even when the animals become gradually less active, they continue to turn away from the light by as definite an angle as when they were first exposed to it. 
3. Comparison of reactions following exposure to light and to dark

Most of the isopods used in the preceding experiments had been living in the dark, but some had been exposed to the daily changes of an ordinary room. No relation was observed between the degree of negative phototaxis and this difference of exposure.

The effect of continued illumination by strong artificial light was tested in a few individuals of both Oniscus and Porcellio. They were placed in a dark room and exposed for a few hours, and in some instances for a longer period, to an electric light, with a rectangular glass jar of water to absorb the heat, between the light and the terrarium. While most of the experiments already described furnish a suitable control on these results, additional tests were made, using animals which had been placed in a dark corner of the room during the time that the other individuals were exposed to light. In a few instances, the same animals were placed alternately in the two habitats.

A comparison of the reactions of isopods from these two sources is shown by the diagrams in figures 9 and 10, and by the angles of negativeness in table 8 .

\section{TABLE 8}

Comparison of the angles of negativeness, following exposure to artificial light and to darkness. Oniscus and Porcellio rathke

\begin{tabular}{|c|c|c|}
\hline & ONIsCUS & PORCELLIO \\
\hline $\begin{array}{l}\text { From light. } \ldots \ldots \ldots \ldots \ldots \ldots \ldots \ldots \ldots \ldots \ldots \ldots \ldots \ldots \ldots \ldots \\
\text { From dark } \ldots \ldots \ldots \ldots \ldots \ldots \ldots\end{array}$ & $\begin{array}{l}117.00^{\circ} \\
112.40^{\circ}\end{array}$ & $\begin{array}{r}67.50^{\circ} \\
103.50^{\circ}\end{array}$ \\
\hline
\end{tabular}

The results after exposure to light are compiled from five individuals each of Oniseus and Porcellio rathkei. The control for Porcellio is compiled from records for ten individuals. That for Oniscus is a summary of the daily reaction for fifteen days of Oniscus A 12 (tables 3 and 4, fig. 7), which was a member of this control series. In the charts, the eight degrees of negative reaction are represented by the abscissae, while the ordinates indicate the proportional number of responses, all the curves being drawn to the same scale. 
A generic difference appears in the results. Oniscus was negative, regardless of previous exposure, with the reaction apparently uninfluenced by strong light. On the other hand, Porcellio showed a high degree of positiveness after exposure to light. A probable explanation for the two modes in the curve for Porcellio (after exposure to light) is that three out of five indi-
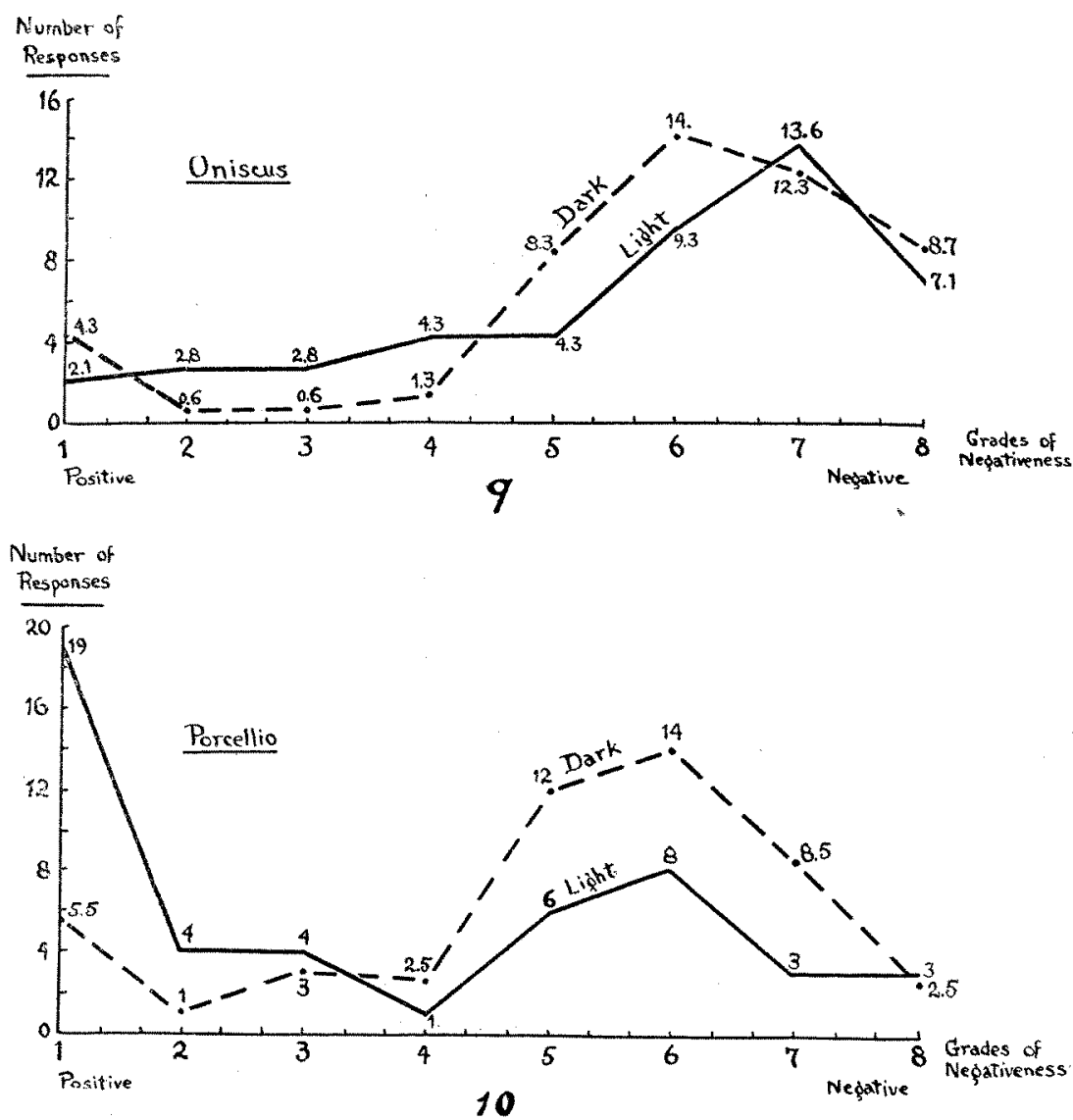

Figs. 9 and 10 Comparison of reactions after exposure to strong artificial light and to dark. Fig. 9, Oniscus; Fig. 10, Porcellio rathkei. Numbers on abscissae indicate grades of negativeness shown in figure 2 . Numbers on ordinates indicate number of responses in each of the eight classes. Fig. 9 shows little difference between the responses of Oniscus under the two conditions. Fig. 10 shows that Porcellio was somewhat positive after exposure to strong light. 
viduals tested were decidedly positive, while the other two were negative. The positive animals were in fact so decidedly positive that two of the three gave positive responses even when they were headed away from the light. The difference is shown in table 9, which summarizes the individual reactions of the five animals after exposure to light, together with a second series of reactions after exposure to dark, made two days later by approximately the same individuals.

In table 9 the numbers are arranged in order of magnitude, but most of the individuals appear in both columns.

TABLE 9

Individual behavior in the species Porcellio rathkei after exposure to light and to dark. Intensity 19.955 C.M.

\begin{tabular}{|c|c|c|c|}
\hline \multicolumn{2}{|c|}{ FROM LIGET (NOVEMBER 20) } & \multicolumn{2}{|c|}{ FROM DARK（NOVEMBER 22) } \\
\hline Identification number & $\begin{array}{c}\text { Angle of negative- } \\
\text { ness }\end{array}$ & Identification number & $\begin{array}{c}\text { Angle of negative } \\
\text { ness }\end{array}$ \\
\hline B8.. & $31.25^{\circ}$ & $\mathrm{C} 11 \ldots$ & $76.50^{\circ}$ \\
\hline B14... & $31.25^{\circ}$ & $\mathrm{C} 12$. & $78.75^{\circ}$ \\
\hline B11....... & $42.75^{\circ}$ & $\mathrm{C} 10 \ldots$ & $108.00^{\circ}$ \\
\hline $\mathrm{B} 12 \ldots \ldots \ldots$ & $99.00^{\circ}$ & $\mathrm{C} 13 \ldots$ & $126.00^{\circ}$ \\
\hline$B 13 \ldots \ldots \ldots \ldots \ldots$ & $130.50^{\circ}$ & $\mathrm{C} 9 \ldots$ & $139.50^{\circ}$ \\
\hline Average........... & $67.50^{\circ}$ & Average........ & $103.50^{\circ}$ \\
\hline
\end{tabular}

These experiments on the influence of preceding illumination, while they were not carried far, indicate the possibility that negative phototaxis in land isopods may be diminished or reversed by exposure to strong light. This appears from the experiments to have been true for some individuals of Porcellio, but the fact that a like result was not obtained from Oniscus makes it less conclusive.

\section{Comparison of reactions of individuals from dry and moist habitats}

The moisture conditions of a habitat are not easily measured, but it is possible to place sowbugs in what must be close to the extremes in which they can live, so far as moisture is concerned. For a minimum of moisture, they can be kept in an environment 
so dry that few individuals of Oniscus survive, Oniseus requiring more moisture in its surroundings than does Porcellio. For a maximum, the substratum can easily be kept saturated with water.

A comparison of the reactions, after keeping the isopods for over a month in these two extreme habitats, is shown in figures 11 and 12.

According to figure 11, Oniscus gave essentially the same negative reaction regardless of preceding moisture conditions. Both curves are typically negative and resemble each other closely.

On the other hand, Porcellio scaber (fig. 12) from the dry habitat was somewhat less negative than the same species from moist surroundings, but both eurves for Porcellio show a considerable degree of indifference to the stimulus.

There is, therefore, little evidence that the reaction varies greatly according to the amount of moisture in an isopod's environment. The chief observable difference in the effect of the two habitats is an increase of activity under dry conditions, which has no apparent relation to the character of the phototaxis. It is interesting that, although, of the two genera, Porcellio is the more adapted to survive atmospheric dryness, lack of moisture should apparently affect its behavior more than that of Oniscus.

\section{Reaction in water}

In studying the amphipod, Orchestia agilis, which spends most of its life out of water, Holmes found ('16, p. 105) that, when thrown into water, these normally positive Crustaceans became at once strongly negative. As sowbugs, when placed in water, will remain active for some time before showing ill effects, it was possible to try a similar test with them. Five individuals each of Oniscus and Porcellio rathkei were placed in a rectangular jar of water and exposed to horizontal light of an intensity close to that used in most of the experiments previously described. The isopods moved about to a considerable extent, but there was no orientation with respect to the position of the light. 
Apparently the unnatural condition of being submerged in water made them indifferent to light.

This change from a negative reaction to indifference corresponds to the changes found by Holmes, in that normal photo-

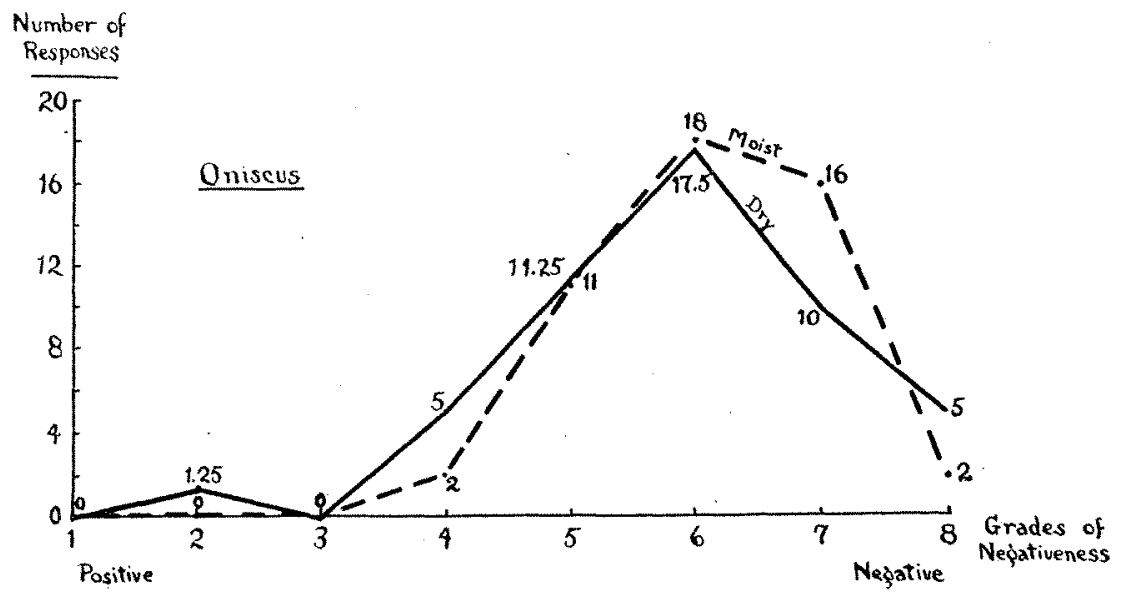

11

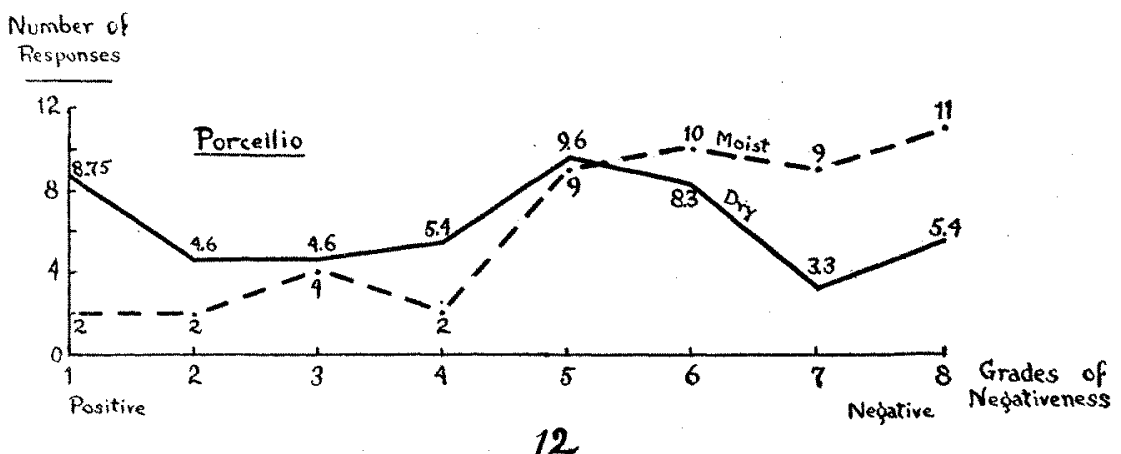

Figs. 11 and 12 Comparison of reactions after exposure to a minimum and maximum of environmental moisture. Fig. 11, Oniscus; Fig. 12, Porcellio scaber. Numbers on abscissae indicate grades of negativeness shown in figure 2. Numbers on ordinates indicate number of responses in each class. Fig. 11 shows practically no difference between the responses of Oniscus under the two conditions. Fig. 12 shows a slight difference in Porcellio under the two conditions, the animals being less negative after living in a dry habitat. 
taxis is altered by throwing the animals into water. The effect is due, according to Holmes' explanation, to unusual contact stimuli.

\section{Comparison of phototaxis in Oniscus and Porcellio}

In the foregoing discussion many references have been made to differences between Oniscus and Porcellio. Any conclusions which may be drawn from these experiments in modifiability of behavior will be more clear after consideration of this generic difference.

A comparative study of the phototaxis of Oniscus and of Porcellio is given in table 10 , which records the angles of negativeness in six series of experiments, most of them already reported in the preceding pages.

TABLE 10

Comparison of angles of negativeness of Oniscus and Porcellio in various phototaxis experiments. A, animal facing light; $B$, animal facing away from light; $C$, right side illuminated; $D$, left side illuminated.

\begin{tabular}{|c|c|c|c|c|c|}
\hline \multirow{2}{*}{ MATERIAL } & \multicolumn{2}{|c|}{ ONISCUS } & \multicolumn{2}{|c|}{ PORCELLIO } & \multirow{2}{*}{ SPEOAES } \\
\hline & $\begin{array}{c}\text { Summary } \\
A, B, C, D\end{array}$ & $\begin{array}{c}\text { Summary } \\
C, D\end{array}$ & $\begin{array}{l}\text { Summary } \\
\mathrm{A}, \mathrm{B}, \mathrm{C}, \mathrm{D}\end{array}$ & $\underset{\mathrm{C}, \mathrm{D}}{\text { Surmmary }}$ & \\
\hline Newly collected......... & $139.50^{\circ}$ & $135.00^{\circ}$ & $110.25^{\circ}$ & $105.75^{\circ}$ & \multirow{3}{*}{$\begin{array}{c}\text { Porcellio } \\
\text { scaber }\end{array}$} \\
\hline From maximum of moisture.... & $123.75^{\circ}$ & $126.00^{\circ}$ & $117.00^{\circ}$ & $119.25^{\circ}$ & \\
\hline From minimum of moisture... & $121.50^{\circ}$ & $123.75^{\circ}$ & $92.25^{\circ}$ & $87.75^{\circ}$ & \\
\hline From dark. & $130.50^{\circ}$ & $122.40^{\circ}$ & $101.25^{\circ}$ & $103.50^{\circ}$ & \multirow{3}{*}{$\begin{array}{l}\text { Porcellio } \\
\text { rathkei }\end{array}$} \\
\hline From strong light. & $114.75^{\circ}$ & $117.00^{\circ}$ & $72.00^{\circ}$ & $67.50^{\circ}$ & \\
\hline At different intensities... & $128.25^{\circ}$ & $126.00^{\circ}$ & $72: 00^{\circ}$ & $61.87^{\circ}$ & \\
\hline
\end{tabular}

As the parallel columns show little differences in the two methods of compiling results, the angles from positions $\mathrm{C}$ and $\mathrm{D}$ will be referred to, whenever, in the discussion, quotations are made from the table.

1. The phototactic response of Oniscus was negative, with little variation in the degree of negativeness under the different conditions. The averages, from the lowest $\left(117^{\circ}\right)$ to the highest $\left(135^{\circ}\right)$, show a range of only $18^{\circ}$, which is less than the difference 
$\left(22.5^{\circ}\right)$ between any two adjoining classes of the eight grades of negativeness (fig. 2). The smallness of this range is shown diagrammatically in figure 13.

2. Porcellio showed a much wider variation, the differences between the lowest $\left(61.87^{\circ}\right)$ and the highest $\left(119.25^{\circ}\right)$ averages recorded being $57.38^{\circ}$. This also is shown in figure 13 ,

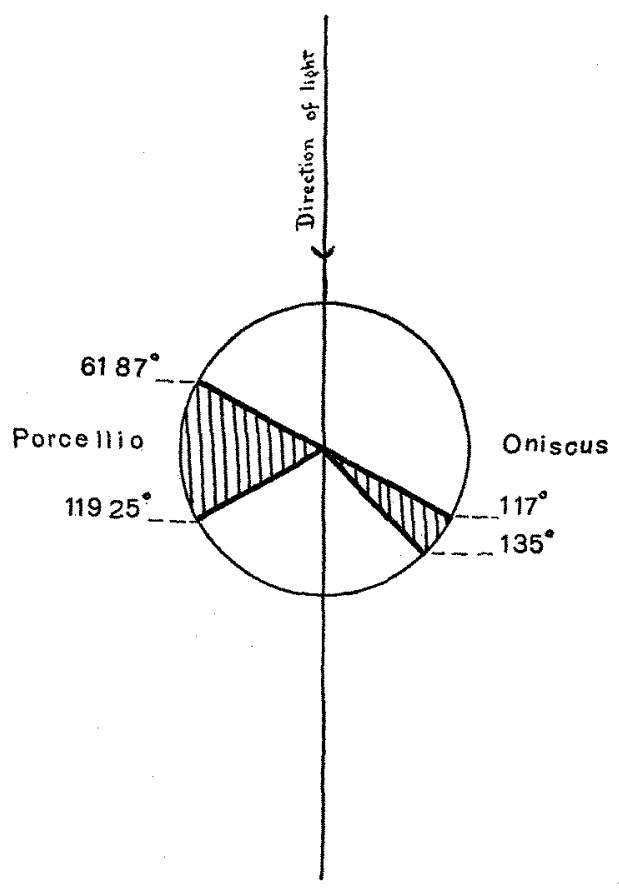

Fig. 13 Diagrammatic representation of the comparison of the reactions of Oniscus and Porcellio given in table 10. The shaded areas show the range of the average angles of negativeness under the six conditions, when the animals were illuminated on the side (positions $\mathrm{C}$ and $\mathrm{D}$ ). Porcellio has a wider range than Oniscus, part of the averages showing a slight turn toward the light.

which shows a considerable degree of variability. In what were probably the more normal of the conditions (i.e., when newly collected, from a dark normal habitat, and from a maximum of moisture), the reaction of Porcellio was negative, but, after continued exposure to strong light and when exposed successively to light of different intensities, the reaction tended to be positive. 
The reactions of the two species of Porcellio appeared in various experiments to be essentially alike, but no comparative tests were made. The present paper deals only with generic differences.

3. Oniscus was more negative than Porcellio under all conditions $^{1}$ in which comparative experiments were made, and, as is shown in figure 13, the range of reaction in Porcellio was much greater. Furthermore, a decided reversal of reaction from negative to positive was observed more frequently in Porcellio than in Oniscus. While in most instances the cause of this reversal was not determined, one apparent cause in the case of Porcellio was continued exposure to strong artificial light (fig. 10 , table 9 ).

4. To summarize the preceding statements, Oniscus and Porcellio are both negative to directive light, but Porcellio is the less negative. The reaction of Porcellio appears to be modified more readily by changes in both internal and external conditions. The possible ecological significance of this difference between the genera will be considered in a later section.

\section{\%. Conclusions}

The reaction of Oniscus is negative under nearly all of the conditions tried and is not easily modified. At times in the course of the experiments, individuals of this species have shown a high degree of positiveness, but the cause for this occasional behavior has not as yet been found in any of the modifying conditions tried. The normal negative phototaxis was lost under the unnatural conditions of an aquatic environment.

${ }^{1}$ In the one instance where there is apparently little difference between the two genera, when the animals were taken from a maximum of moisture, the real contrast is shown by a comparison of figures 9 and 10 . The arithmetical mean (A.M.), from which the figures for the angle of negativeness were derived, was similar in the two instances, but the true distinction is shown by the average deviation (A.D.), and by calculating the coefficient of variability (C.V.) by the formula $C . V .=\frac{A . D}{A \cdot M} . \quad$ The results are shown in a table.

\begin{tabular}{|c|c|c|}
\hline & A.M. & A.D. \\
\hline Oniseus..................... & 6.1 & 0.741 \\
\hline Porcellio $\ldots \ldots \ldots \ldots \ldots \ldots \ldots \ldots \ldots \ldots$ & 5.8 & 1.555 \\
\hline
\end{tabular}


According to the experiments, the behavior of Porcellio appears to be somewhat modified by external conditions. These animals were less negative after living in a dry atmosphere, after exposure to strong light, and when exposed successively to different intensities. The most striking result was a reversal to positiveness which occurred in certain individuals after exposure to strong light (fig. 10, table 9).

As was shown in the preceding section, the normal phototaxis of Porcellio shows a great amount of variation, and hence it is difficult to say to what extent these modifications are actually due to the external conditions of the experiments.

\section{DISCUSSION}

\section{A. ECOLOGICAL ANALYSIS}

Ecology is the study of the relation between organisms and their environment. Ecological studies deal both with the distribution of animals and plants and with adaptation, which may be defined as the sum of the structural and functional methods by which the organism is fitted to its environment. The word adaptation is used without implying any theory as to the cause of adaptation. Inasmuch as the present emphasis of studies in animal and plant ecology is particularly on adaptations of a physiological nature, the study of animal behavior has become of increasing ecological importance.

One of the essential distinctions between structure and behavior is that structure, in the main, is dependent on genetic relationships, while behavior is closely related to the nature of the environment. Without attempting to settle the problem whether environment is the cause of behavior, the facts remain that animals of various structures tend to have the same behavior, if they occupy the same environment (Shelford, '14, '16) and that individuals of a single species from different environments often have a difference in behavior corresponding to the environment (Allee, '12, '14; Adams, '15). A particular plan of structure may be suited to a wide variation in environment, provided that the behavior of the animal varies according to the 
environment. Because of this fact, such diverse animals as annelid worms, gasteropods, and crustaceans, which are all found in a wide variety of habitats, frequently occur together in the same ecological association.

The environmental importance of behavior characters is shown further in a discussion by Vestal ('14), in which he compares in detail five sets of characters - structural, physiological, psychological, biographical, and numerical. Vestal concludes that, at least so far as competition with other animals is concerned, 'psychological' or, as he preferably calls them in another connection, behavior characters, are actually the most important of all.

In order to discuss intelligently the significance of the phototaxis of land isopods, a partial ecological analysis of these animals will be given.

\section{Habitat}

A habitat analysis may be made on the basis of a table by Adams ('15, p. 95), which summarzizes for comparative purposes the habitats of prairie and forest invertebrates. The ground stratum of the forest, which land isopods typically occupy, is a region where they are exposed, comparatively speaking, to a large amount of humidity; a small amount of evaporation, and a fairly constant temperature. For animals only slightly adapted to land life, these appear to be the optimum conditions.

\section{Structural and physiological adaptations}

A brief discussion will be given of a few of the characteristics of land isopods which make possible their living in a habitat furnishing the conditions just mentioned.

a. Respiration. Land isopods have a somewhat generalized crustacean structure, with a hard outer covering of chitin, which prevents evaporation of water from the body. The organs of respiration, as in the aquatic isopods, are modified abdominal appendages (pleopods). The nature of the mechanism of respiration is still somewhat in doubt, although the subject has 
always been the center of interest in these animals, and recent studies have been made by Stoller ('99), Bepler ('09), Bernecker ('09), Unwin ('09), Müller ('10), and Herold ('13). The following statements represent perhaps the most widely accepted opinion among these investigators.

1. In most and probably all genera the thin-walled inner branches (endopodites) of the pleopods are used for respiration. They are covered and thus protected by the outer branches (exopodites) and are kept moist by glandular secretions.

2 . The outer branches in most forms, besides serving as a protection for the inner branches, have trachea-like modifications for breathing atmospheric air. Of the two genera used in the experiments reported in the present paper, Porcellio has these structures better developed than Oniscus. Correlated with this fact is the ability of Porcellio to live in drier situations than Oniscus. Of the species of Porcellio, P. rathkei is somewhat better adapted to air-breathing than $P$. scaber.

3 . The character of the endopodites resembles closely that of the same structures in Asellus communis, the fresh-water isopod previously referred to. The most primitive land isopods, the family Ligydidae, have 'gills' closely resembling those of Asellus. This seems to indicate that isopods as a group were particularly suited to a change from water to land, since only slight modifications in the respiratory mechanism proved necessary.

b. Food. The food and feeding habits of land isopods and of Asellus have been investigated, respectively, by Murlin ('02) and Banta ('10, p. 477). Both kinds of animals exercise little selection in their choice of food and take a large percentage of inorganie matter into the digestive tract with the food.

c. Care of young. The developing young of isopods remain in a brood-pouch on the ventral surface of the female until they have developed into the adult strueture. In this way the young are protected during their early existence and no special device during the early stages is necessary to adapt them to land life. d. Behavior. So far as respiration, feeding habits, and protection of developing young are concerned, land isopods are little different from their aquatic relatives. The isopod plan of 
structure seems to be suited to terrestrial as well as aquatic life. However, land isopods are confined to a limited, protected environment, and are not suited, like insects, to become dominant land animals. The fact that they remain in the environment in which they are fitted to survive is probably due chiefly to another set of characters, those which make up the behavior. These characters will now be considered.

\section{Reactions of land isopods}

Although the entire behavior complex is involved in adaptation, it is possible to make a partial analysis into reactions to various classes of stimuli. Among the most important factors of the environment of land animals are humidity, evaporation, contact, and light.

a. Reactions to humidity and evaporation. So far as observation shows, the effect on land isopods of exposure to a dry atmosphere, including the first effect in desiccation experiments, is an increase of activity. This is a useful adaptation, provided the activity carries them to other regions where moisture conditions approach more nearly the optimum.

The problem whether these animals have a definite reaction to differences in humidity and evaporation has not been investigated. The most satisfactory method yet devised for making such tests is doubtless that of Shelford for testing reactions to the evaporating power of air. Among the species of animals in which he has found such a response (Shelford, '13 a) are several commonly associated with sowbugs, including ground beetles, salamanders, snails, and the yellow-margined millipede (Fontaria corrugate Wood). No similar experiments have thus far been recorded for land isopods, but it is quite possible that they, too, give a negative reaction to increased evaporating power of air, and as a result remain in places where evaporation is at a minimum. The somewhat unusual occasions when they visit exposed places may possibly be only at times when there is a large amount of atmospheric humidity. 
b. Reactions to contact. Isopods as a group have the general plan of structure common to contact animals, as is seen best of all in the oval bodies, with flattened ventral surfaces, which characterize the Oniscoidea. Positive thigmotaxis is doubtless an important factor in keeping them in a suitable habitat. The use of the sense of contact as a substitute for the sense of sight has already been referred to (page 198).

c. Reactions to light. With the recognition that land isopods are contact animals and that further studies will probably show reactions to other classes of stimuli, the part in their normal life played by the reaction to light remains to be considered. Since studies of the reaction, both to artificial light and to daylight, have shown that sowbugs are decidedly negative, even to low intensities and since the reaction is constant under most conditions, it seems reasonable to conclude that negative phototaxis is a character to be considered in an ecological interpretation of these animals.

Inasmuch as sowbugs usually live in the dark, it seems probable that during the greater part of the time light is not an influential factor in their lives. When, however, they accidentally wander from their places of concealment, their reaction to light may be expected to turn them back again into the dark. Their actual behavior out of doors when exposed to light can be observed when a log or other object concealing them is overturned. Under these conditions, some of the sowbugs become active at once, soon disappearing in crevices or under the log, while others erouch down motionless. In the latter case, when thigmotaxis apparently overcomes phototaxis, the result is only temporary, for in a short time no sowbugs are in sight. Although the light is so diffuse that it cannot direct their course as unmistakably as under experimental conditions, yet its influence seems sufficient to carry them to dark places and to keep them there. From this fact it may be concluded that light serves as a stimulus to turn them back whenever they wander into it in the course of their ordinary activities. The same is probably true in the early morning, whenever they leave their places of concealment at night. 
The fact that the reaction of Porcellio appeared from the experiments to be less negative than that of Oniscus is correlated with other generic differences. Porcellio, because of the structure of its respiratory appendages, is better provided for living in dry situations than is Oniseus, and hence has perhaps less need of a definite negative reaction to keep it in its proper environment.

Furthermore, the phototaxis of Porcellio seems to be reversed from negative to indifferent or positive more easily than that of Oniscus. This has been observed under natural as well as experimental conditions. A good example was noted at Cold Spring Harbor, Long Island, in July, 1916, when Porcellio was found commonly for three or four days on green plants at a height of four or five feet from the ground. Among the possible causes for this unusual behavior was a partial or complete flooding of the ground habitat, but, whatever the cause, it was apparently accompanied by a reversal from the usual negative phototaxis, with perhaps also a reversal of geotaxis.

Table 10 also suggests, although in this case it does not offer a suitable basis for comparison, that possibly Porcellio rathkei is less negative than $P$. scaber. If so, this furnishes a further correlation, since, as has been mentioned, the breathing appendages of $P$. rathkei are, of the two species, the better adapted to air respiration, and its habitat is probably slightly less restricted.

Whether or not it is possible to find any evolutionary significance in this behavior, it is, at any rate, worth while to compare the phototaxis of land and of water isopods. The most complete study of the light reactions of any aquatic isopods which has yet been made is that by Banta ('10). Table 11 compares the results for Oniscus, recorded in the present paper, with Banta's summary ('10, p. 268) of the reactions of Asellus communis.

This comparison indicates that, of the two genera, Oniscus is the more definitely negative. The negative reaction helps to prevent Oniscus from leaving its habitat in the daytime, while Asellus, with no such restricted habitat, is at definite times positive to light. 
TABLE 11

Comparison of phototaxis of Oniscus asellus (this paper) and of Asellus communis (Banta'10, p. 268)

\begin{tabular}{l|l}
\hline \multicolumn{1}{c|}{ oniseus } & \multicolumn{1}{c}{ Asmbuts } \\
\hline $\begin{array}{l}\text { Reacts to intensities as low as 0.0119. } \\
\begin{array}{l}\text { Negative to light, regardless of pre- } \\
\text { vious exposure }\end{array}\end{array}$ & $\begin{array}{l}\text { Does not react to intensities of 1 C.M. } \\
\text { or less } \\
\text { Negative after exposure to diffuse day- } \\
\text { light } \\
\text { Positive for a few hours after exposure } \\
\text { to darkness }\end{array}$ \\
\hline
\end{tabular}

When Porcellio is compared with Asellus, the contrast is not so striking, because Porcellio is somewhat like Asellus in not being always negative. However, the fact that Porcellio, like Oniscus, responds to intensities as low as 0.0119 C.M. suggests that it, too, is more discriminating in its reaction to light than Asellus. Whether or not negative phototaxis was intensified as an adjustment to land life, it at least appears to be a more important factor in the activities of land isopods than of aquatic isopods.

In this connection a few observations will be given concerning one of the most primitive of land isopods, so regarded because its structure is less specialized for life on land. The large active isopod, known as the sea slater (genus Ligyda), lives in crevices of rocky shores just above the high-tide line among the San Juan Islands of the northern part of Puget Sound. At low tide these isopods emerge from their hiding-places and migrate down the rocks nearly to the low-tide line. During this period they can often be seen moving about with apparent disregard of the bright sunlight. At other times, however, they are found in crevices, and in the laboratory they give a negative reaction to sunlight. In their case the reversal of reaction keeps them in the damp region close to the water's edge, so perhaps it is advantageous for them not to have so consistent a negative reaction. to light as that of Oniscus.

From this ecological study of the phototaxis of land isopods it may be concluded that the usual negative phototaxis is advan- 
tageous to this group of animals, because it keeps them in a suitable habitat. Such reversals of reaction as occur are probably adaptive also. Unless other reactions are so important as to overcome the influence of the phototaxis in ways not yet determined, observations and experiments indicate that this reaction is an important ecological character, and, further, that it may have been one of the factors which made possible the migration of the ancestors of the present land isopods from water to land.

\section{B. THE PROBLEM OF ORIENTATION}

In addition to the ecological analysis, a few observations can be related to the problem of orientation, which has a large place in behavior studies. The subject of orientation has been so thoroughly discussed, particularly in such general works as those of Jennings ('06), Mast ('11), Loeb ('16), and Holmes ('16), that no extended introduction is necessary. A distinction which Darwin ('80) made, according to Mast, is, however of importance. To quote from Mast ('11, p. 47): "To explain orientation, Darwin said, we do not need to account for movement; it is only necessary to account for changes in the direction of movement."

The problem is well formulated by Bancroft ('13) in two questions which he applies to Euglena, but which could be asked equally well with regard to any other organism:

1. Does Euglena become oriented to light as directly as its method of orientation admits, or does it orient indirectly by the method of trial and error? In either case the reaction will be heliotropic, but the method of orientation will be different.

2. Is heliotropism in Euglena brought about by response to temporal changes in light intensity, or is it caused by the continuous action of the light independent of changes in intensity?

This division of the subject by Bancroft into two distinct problems avoids a source of confusion which has occurred in most discussions of the question. 


\section{Direct orientation versus method of trial}

The study of Torrey and Hays ('14) on the orientation of Porcellio to light resulted in the conclusion that orientation is direct and that the many preliminary movements of the antennae before locomotion, which appear to correspond to the 'random movements' in the forms studied by Holmes ('05), have no relation to orientation. These authors concluded that: "The consistency with which many individuals turned away from the light, whether the latter was on one side or the other, left no room for doubt that the reaction was forced in a definite direction."

Although the present investigation was not made specifically to determine the mechanics of response, observations in the ordinary experiments indicated that there is a definite orientation, which is little obscured by random movements. In the usual negative responses there is a time difference which makes possible a division into three classes of responses: 1) those in which orientation occurs without locomotion; 2) those in which orientation occurs abruptly at the beginning of locomotion; 3) those in which orientation occurs gradually during locomotion. Of these, the first is not frequent, although a characteristic response, while the second and third are both common. The third method, where orientation is secured by a gradually curved course, is in reality just as direct as the other two. If necessary allowance is made for individual peculiarities in the response, due probably to internal eauses, the response seems to involve a direct orientation by the light, in which trial movements do not play any essential part.

\section{Constant intensity versus change of intensity}

The basis of most present discussions of orientation is, however, the second of those quoted from Bancroft, the question whether the response is due to continuous stimulation from light acting at a constant intensity or to the shock resulting from changes of intensity. A possible contribution to the solution of this problem may be found in an analysis of the frequent delays before response. Even when an isopod responds vigorously at 
first, the delay sets in on the average after ten responses, so that in nearly every ordinary series of twenty trials some responses occur only after an interval.

When an animal does not respond to the initial light stimulus, there are three possible explanations why it responds later. These are: 1) a delayed response to the initial stimulus; 2) a response to the continuous stimulus, and 3) a response due to causes wholly other than light stimuli. Whichever of these is true, the difference between immediate and delayed response is a difference in photokinesis rather than in phototaxis, because orientation is quite as definite when the response is delayed as when it is immediate.

The opportunity for observing the influence of continuous stimulation after delayed reaction is found in those instances when orientation occurs before locomotion, whether or not it is accompanied by locomotion. Under these circumstances, the first locomotor movement of the animal after a delay is a turning movement, and the cause of the turning cannot be found in any change of intensity which has occurred since the initial stimulus on the eyes of the animal. That is, the reaction under these conditions must be due either to the continuous constant stimulus or to an after-effect of the shock produced by the initial stimulus.

This raises the further question: Would an isopod give an orienting response after a delay if the stimulus were not continued? Mast ('12) tested fireflies from this point of view, and in his summary says:

The males do not orient when exposed to continuous illumination. They respond only to flashes of light and the reaction does not begin until after the light has disappeared. Removal of the female immediately after she glows has no effect on the reaction. Thus orientation may take place in total darkness, and it is surprising how accurately these animals turn through the proper angle in the total absence of the stimulating agent. Here we have a case in which it is clearly demonstrated that light does not act continuously in the process of orientation as demanded by Loeb's theories, a case in which it is also clearly demonstrated that the continuous action of the stimulating agent is not necessary to keep the organism oriented. 
This statement is not at all surprising, because sudden flashes of light are a part of the natural environment of the firefly, and the firefly is adapted to them in a unique way. On the other hand, since most animals are exposed to constant illumination and to gradual changes rather than to sudden changes, the firefly is hardly a typical animal in which to test out this point.

For this reason an experiment was devised to determine whether Oniscus can be oriented after a delay, in the absence of the original stimulus. Twelve individuals of Oniscus were tested in the position facing the light, according to the usual method. Record was made only when there was a delay in response lasting more than five seconds. In approximately half of these instances of delayed response in each animal, the light was turned off after five seconds; in the other half the animals were exposed to the light until they responded. (If no response occurred during 60 seconds, it was recorded as 'no response.') The course taken by the animal and the interval before response were both recorded in each instance. The individual animals were given repeated stimuli until several delayed responses had been recorded under each of the two conditions.

In order to observe the animal after the light was turned off, the influence of overhead lights was tested until one was found so dim as not to affect the accuracy of orientation and yet strong enough to make it possible to wateh the movements of the animals. In a preliminary test series with the light finally chosen, five individuals of Oniscus showed an average angle of negativeness of $126^{\circ}$, which is thoroughly normal, and shows that the overhead light did not disturb the normal reaction to horizontal illumination. This light was, therefore, used during the entire experiment.

The result is shown in figure 14 and table 12 . According to figure 14, the greatest number of responses when the light had been turned off fell into class 1 on the abscissa, with a gradually decreasing number of responses in the other classes. This shows that the animals moved in general in the direction in which they were headed, with no apparent response to the initial light stimulus. On the other hand, the curve of the responses when the 
TABLE 12

Comparison of reactions of Oniscus after delay when light is continuous and when light is extinguished after 5 seconds. Intensity, 12.79 C.M.

\begin{tabular}{|c|c|c|}
\hline & $\underbrace{\text { LIGET }}_{\text {WITH CONTINUOUS }}$ & $\begin{array}{c}\text { WTHOUT CONTINUOUS } \\
\text { LIGHT }\end{array}$ \\
\hline 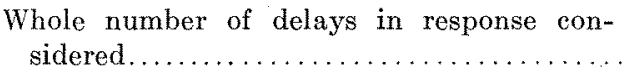 & 84 & 80 \\
\hline Responses after delay. & 58 (69 per cent) & $50(62.5$ per cent $)$ \\
\hline Failures to respond after delay.. & 26 & 30 \\
\hline Average interval before delayed response. & 31.7 seconds & 34.6 seconds \\
\hline $\begin{array}{l}\text { Average angle of negativeness in delayed } \\
\text { response } \ldots \ldots \ldots \ldots \ldots \ldots \ldots \ldots \ldots \ldots \ldots\end{array}$ & $76.50^{\circ}$ & $49.50^{\circ}$ \\
\hline
\end{tabular}

Number of

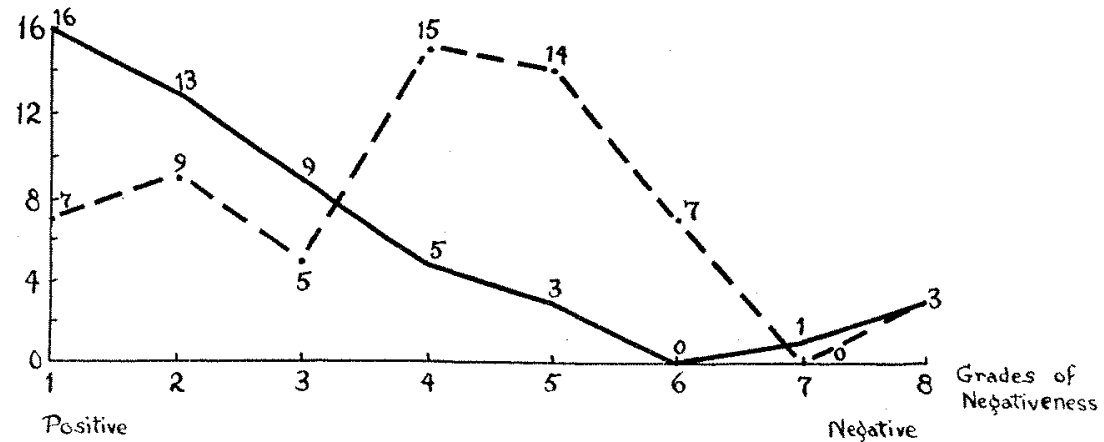

Fig. 14 Comparison of responses of Oniscus in instances of delayed response, when the light is turned off after five seconds (solid line) and when the light is continued (broken line). Numbers on abscissa indicate grades of negativeness in figure 2. Numbers on ordinate indicate number of each type of response. Shows practically no response after delay unless the light is continued.

light was continuous is nearly typical for the ordinary negative reaction of an animal facing the light. (Compare with $A$ in figs. 6 and 7.) This set of responses after delay has a larger proportion of positive responses than was shown in figures 6 and 7 , but it forms essentially the same type of curve and is quite different from the results when the light was turned off. The same difference is shown, though less noticeably, in table 12 , where the angles of negativeness differ by $27^{\circ}$. 
According to table 12 , the length of the intervals before response and the percentage of response after delay are essentially the same under the two conditions of the experiment. This is, however, probably a matter of photokinesis rather than of phototaxis.

From this experiment it may be concluded that orientation in land isopods occurs after delayed response only when the stimulus is continuous. In other words, if the initial stimulus is not sufficient to bring about immediate response, the stimulus must be continued in order for orientation to occur. Since, then, the response to a continuous constant intensity can occur in cases of delayed response, there appears to be no reason why the same type of stimulus cannot be a cause of the reaction when the response is not delayed.

\section{Conclusions}

From the preceding experiments and diseussion the following conclusions may be drawn:

$a$. Orientation of land isopods appears to be direct, and not the result of a selection of random movements.

$b$. Orientation is at times due to the continuous action of light acting at constant intensity, even though it may also be due to the shock produced by changes of intensity.

\section{SUMMARY}

A study of the reactions to light of three species of land isopods, Oniscus asellus, Porcellio rathkei, and Porcellio scaber, resulted in the following conclusions:

1. Land isopods respond to light stimuli in three ways: by photokinesis, by phototaxis, and by vision. Vision is, however, only slightly developed. The experiments were confined to phototaxis.

2. Oniscus is negative to diffuse daylight and to controlled horizontal illumination by artificial light. The latter was shown in detail by a study of the percentage of negative responses, by a graphical representation of the degree of turning away 
from the light, and by calculation of the average 'angle of negativeness.'

3. Porcellio is in general negative to the same stimuli as Oniscus, but is, of the two genera, the less consistently negative.

4. Oniscus and Porcellio were found to respond to a range of intensities from 100 C.M. to 0.01 C.M. The response is the same to all intensities. On account of the extreme sensitiveness to low intensities, the threshold of stimulation was not determined.

5. No consistent change in the phototaxis of Oniscus was caused by repetition of stimuli. Under these conditions, the animal usually became less active, but accuracy of orientation was not interfered with.

6. The reaction of Oniscus was essentially the same whether previously exposed to strong light or to dark and whether kept in a maximum or minimum of moisture. Porcellio was somewhat less negative after living in a dry habitat, and some individuals of this genus were found to be positive after exposure to strong light.

7. When the isopods were immersed in water, they did not respond to light.

8. Land isopods are not greatly different structurally from their aquatic relatives. They are confined to a limited habitat on the land, where humidity is comparatively high and the evaporating power of the air is relatively low.

9. Negative phototaxis appears to be a factor in keeping these animals in a suitable habitat, and is thus important in fitting them for life on land.

10. Oniscus, with a more restricted habitat than Porcellio, has a more consistent negative reaction to light.

11. Land isopods are more definitely negative to light than the fresh-water isopod, Asellus communis. Negative phototaxis appears to be a more important ecological factor for land isopods than for aquatic isopods.

12. Oniscus appears to be oriented directly by light, and to respond, at least under some circumstances, to a continuous light stimulus acting at a constant intensity. 


\section{BIBLIOGRAPHY}

Adams, C. C. 1913 Guide to the study of animal ecology. New York. 1915 An ecological study of prairie and forest invertebrates. Bull. IIl. State Lab. Nat. Hist., vol. 11, pp. 33-280.

Allee, W. C. 1912 An experimental analysis of the relation between physiological states and rheotaxis in Isopoda. Jour. Exp. Zoöl., vol. 13, pp. $260-344$

1914 The ecological importance of the rheotactic reaction of stream isopods. Biol. Bull., vol. 27, pp. 52-66.

BANCROFT, F. W. 1913 Heliotropism, differential sensibility, and galvanotropism in Euglena. Jour. Exp. Zoöl., vol. 15, pp. 383-428.

BANTA, A. M. 1910 A comparison of the reactions of a species of surface isopod with those of a subterranean species. Jour. Exp. Zoöl., vol. 8, pp. 243-310, 439-488.

Bepler, H. 1909 Über die Atmung der Oniscoideen. Inaug.-Diss. Greifswald.

Bernecker, A. 1909 Zur Histologie der Respirationsorgane bei Crustaceen. Zool, Jahrb., Abt. f. Anat., Bd. 27, S. 583-630.

CoLE, L. J. 1907 An experimental study of the image-forming powers of various types of eyes. Proc. Am. Acad. Arts and Sci., vol. 42, pp. $335-417$.

Darwin, C., and Darwin, F. 1880 Power of movement in plants. London.

Herold, W. 1913 Beiträge zur Anatomie und Physiologie einiger Land-isopoden. Häutung-Sekretion-Atmung. Zool. Jahrb., Abt. f. Anat., Bd. 35 , S. $457-526$.

Holmes, S. J. 1905 The selection of random movements as a factor in phototaxis. Jour. Comp. Neur., vol. 15, pp. 98-112.

1916 Studies in animal behavior. Boston.

Jennivgs, H. S. 1906 Behavior of the lower organisms. New York.

Loeb, J. 1916 The organism as a whole. New York.

Ast, S. O. 1911 Light and the behavior of organisms. New York.

1912 Behavior of fire-flies (Photinus pyralis)? with special reference to the problem of orientation. Jour. Animal Behavior, vol. 2, pp. $256-272$.

Müller, G. W. 1910 [Über die Atmung der Landasseln]. Mitt. nat. Ver. Neu-Vorpommern, Rügen Jahrg., Bd. 41, S. 21-22. [Not seen by writer.]

Murur, J. R. $1902^{\circ}$ Absorption and secretion in the digestive system of the land isopods. Proc. Acad. Nat. Sc., Philadelphia, vol. 54, pp. 284-359.

PATten, B. M. 1917 Reactions of the whip-tail scorpion to light. Jour. Exp. Zoöl., vol. 23, pp. 251-275.

Richardson, H. 1905 A monograph on the isopods of North America. Bull. U. S. Nat. Museum, no. 54 .

Shelford, V. E. 1913 Animal communities in temperate America. Chicago. 1913 a The reactions of certain animals to gradients of evaporating power of air. A study in experimental ecology. (With a method of establishing evaporation gradients by V. E. Shelford and E. O. Deere.) Biol. Bull., vol. 25, pp. 79-120. 
Shelford, V. E. 1914 An experimental study of the behavior agreement among the animals of an animal community. Biol. Bull., vol. 26, pp. 294-315.

1916 Physiological differences between marine animals from different depths. Puget Sound Marine Sta. Pub., vol. 1, no. 14, pp. 157-174.

Stoller, J. H. 1899 On the organs of respiration of the Oniscidae. Zoologica, Bd, 10, Heft 25.

Torrex, H. B., And HaYs, G. P. 1914 The rôle of random movements in the orientation of Porcellio scaber to light. Jour. Animal Behavior, vol. 4, pp. 110-120.

Unwis, E. E. 1909 The respiration of land isopods. Irish Natural., vol. 17, p. 236; Rep. 78th Meet. Brit. Ass. Adv. Sc., pp. 736-737.

Vestala, A. G. 1914 Internal relations of terrestrial associations. Am. Nat., vol, 48 , pp. 413-445. 